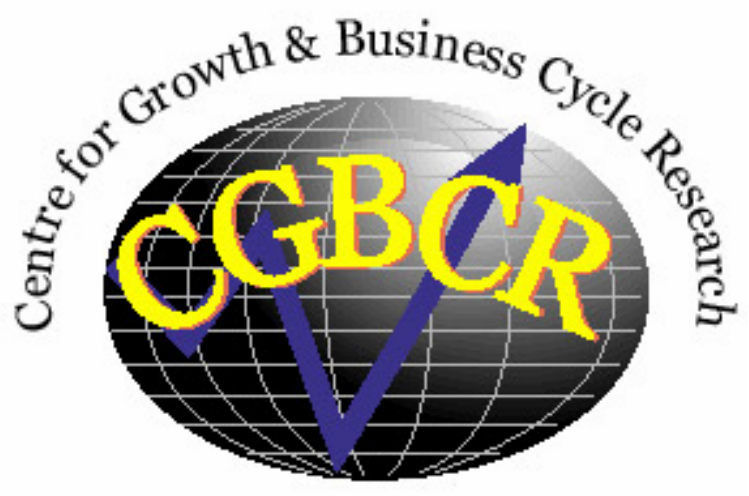

Discussion Paper Series

\title{
A Theory of Infrastructure-led Development
}

By

\section{Pierre-Richard Agénor}

Centre for Growth and Business Cycle Research, Economic Studies, University of Manchester, Manchester, M13 9PL, UK

December 2006

Number 083

Download paper from:

http://www.ses.man.ac.uk/cgbcr/discussi.htm 


\title{
A Theory of Infrastructure-Led Development
}

\author{
Pierre-Richard Agénor* \\ Final version: February, 52010
}

\begin{abstract}
This paper proposes a theory of long-run development based on public infrastructure as the main engine of growth. The government, in addition to investing in infrastructure, spends on health services, which in turn raise labor productivity and lower the rate of time preference. Infrastructure affects the production of both commodities and health services. As a result of network effects, the degree of efficiency of infrastructure is nonlinearly related to the stock of public capital itself. This in turn may generate multiple equilibria. Provided that governance is adequate enough to ensure a sufficient degree of efficiency of public investment outlays, an increase in the share of spending on infrastructure (financed by a cut in unproductive expenditure or foreign grants) may facilitate the shift from a low growth equilibrium, characterized by low productivity and low savings, to a high growth steady state.
\end{abstract}

JEL Classification Numbers: O41, H54, I28.

*Hallsworth Professor of International Macroeconomics and Development Economics, University of Manchester, and Centre for Growth and Business Cycle Research. I am grateful to Keith Blackburn, Peter Montiel, Kyriakos Neanidis, Devrim Yilmaz, participants at seminars at the Universities of Naples (Parthenope) and Clermont-Ferrand, and two referees for helpful discussions and comments on a previous draft. I also thank Steven Pierce for providing relevant historical references on the role of infrastructure (or, rather, the lack thereof) in Sub-Saharan Africa. The views expressed here are my own. 
Means of communication were not constructed in the colonial period... to facilitate internal trade in African commodities. There were no roads connecting different colonies and different parts of the same colony in a manner that made sense with regard to Africa's needs and development. All roads and railways led down to the sea. They were built to extract gold or manganese or coffee or cotton. They were built to make business possible for the timber companies, trading companies and agricultural concession firms, and for white settlers.

Walter Rodney, How Europe Underdeveloped Africa (1973, Chapter 6).

\section{Introduction}

Lack of infrastructure continues to be a key obstacle to growth and development in many low-income countries. In Sub-Saharan Africa in particular, only 16 percent of roads are paved, and less than one in five Africans has access to electricity. Transport costs are the highest in the world and act as a significant constraint on trade expansion. Yoshino (2008) for instance found that poor quality of public infrastructure - measured in terms of the average numbers of days per year for which firms experience disruptions in electricity - has an adverse effect on exports in sub-Saharan Africa. In Rwanda, farmers receive only 20 percent of the price of their coffee as it is loaded onto ships in Monbasa; the other 80 percent disappear into the costs of poor roads (as well as red tape) between Rwanda and Kenya.

To alleviate these constraints to growth and poverty reduction, several observers have advocated a large increase in public investment in infrastructure, in line with the "Big Push" view of Rosenstein Rodan (1943). ${ }^{1}$ A common argument for doing so is that infrastructure services have a strong

\footnotetext{
${ }^{1}$ Actually, most of Rosenstein Rodan's article is dedicated to the role of complemetarities between industries, not to a large increase in public investment. However, in keeping with tradition, we will credit the "Big Push" view to him.
} 
growth-promoting effect through their impact on production costs, the productivity of private inputs, and the rate of return on capital-particularly when, to begin with, stocks of infrastructure assets are relatively low. More recent research, however, has emphasized that infrastructure may also affect growth indirectly through a variety of channels, most notably by affecting health outcomes. ${ }^{2}$ Access to clean water and sanitation helps to improve health and thereby productivity. By reducing the cost of boiling water, and reducing the need to rely on smoky traditional fuels (such as wood, crop residues, and charcoal) for cooking, access to electricity also helps to improve hygiene and health - in the latter case by reducing indoor air pollution and the incidence of respiratory illnesses.

Dwelling in part on this evidence, this paper presents a theory of development based on public infrastructure as the main engine of growth. In doing so, I deliberately leave aside two other powerful forces that have been identified in the literature: human capital accumulation and endogenous technological progress (see, for instance, Kosempel (2004)). In the model, the growth rate depends on the interactions between infrastructure, health, and savings. Infrastructure raises the economy's ability to produce health services; in turn, greater access to health services enhances workers' productivity, and therefore output. Thus, the accumulation of human capital results not from the acquisition of knowledge, but from better quality of effective labor. Unlike endogenous growth models in the Uzawa-Lucas tradition, this requires thinking of knowledge as embodied in workers, as opposed to books and libraries. In addition, improvements in health raise incentives to save. This effect occurs not through its direct impact on life expectancy - given

\footnotetext{
${ }^{2}$ See Agénor and Neanidis (2006) and Agénor (2009b) for a more detailed discussion of these channels, and Wang (2003) and Wagstaff and Cleason (2004) for some empirical evidence.
} 
that the representative household in the model is infinitely-lived - but by reducing the degree of impatience, or equivalently, preference for the present. In turn, a lower time preference rate raises the marginal utility of future consumption and stimulates savings, which promotes physical capital accumulation and growth.

I also assume, crucially, that the degree of efficiency of public infrastructure is positively (and nonlinearly) related to the stock of public capital itself. The threshold variable is the stock of capital per worker, as suggested by Fernald (1999). The introduction of this external effect leads to multiple equilibria. The realization of a specific steady-growth equilibrium depends therefore on expectations of private agents and the initial position of the economy - including the parameters characterizing public policy.

The existence of a nonlinear relationship between the efficiency of public capital and its level can be motivated in two ways. The first is based on the view that infrastructure investment is lumpy, that is, a certain quantity of infrastructure assets must be accumulated before it begins to contribute at all to the production activities of the private sector. However, lumpiness can explain piecewise-linear threshold effects, but not necessarily nonconvexities. The second is based on network effects. Economies of scale due to network externalities are a widely recognized imperfection in infrastructure services (see World Bank (1994)). An important characteristic of modern infrastructure is indeed the fact that services are often supplied through a networked delivery system designed to serve a multitude of users. This interconnectedness means that the benefits from investment at one point in the network will generally depend on capacities at other points. Put differently, inherent to the structure of a network is that many components are required for the provision of a service; these components are thus complementary to 
each other. Having electricity to produce commodities in rural areas but no roads to carry them to urban markets limits the productivity effects of a program designed to increase access to energy. In that sense, electricity and roads are complementary components of the infrastructure network, and only joint availability or operation will generate efficiency gains, that is, positive externalities.

The network character of infrastructure capital may therefore induce a strong nonlinearity in its productivity. Until the network is built, public capital has a low (or even null) marginal productivity. Once the basic parts of a network are established, and a critical mass has been reached, strong gains are associated with small additional increases in infrastructure investment. But beyond that, the productivity gains induced by additional investments tend to slow down. Thus, in contrast to much of the literature on network externalities, which is static in nature (as noted by Economides (1996)), the perspective adopted here is explicitly dynamic.

This second interpretation carries substantial weight for understanding the current plight of many poor countries. As noted earlier, inadequate transport networks remain a key characteristic of Sub-Saharan Africa today. Moreover, a number of observers have argued that the current state of affairs is intimately linked to the history of the continent. Colonization and a focus on resource extraction dramatically affected the use of space in the region, shifting growth and urbanization from inland to coastal areas. Many African capitals today are ports that were built at the end of railways designed to carry flows of raw materials and labor from the inland. Historians like Cooper (1993), as well as geographers and political scientists - particularly those in the Marxist tradition, like Walter Rodney (1973), in his classic book How Europe Underdeveloped Africa, as quoted above - have long pointed out that 
transport networks inherited from that growth were located perpendicularly to the seashores, and were not built to occupy space widely. ${ }^{3}$ As indicated earlier, however, I go beyond a "pure" infrastructure (or physical capital) view of development by accounting for the impact of infrastructure on the production of health services and endogenizing the impact of health on labor productivity and savings. The model illustrates therefore the crucial links between public infrastructure accumulation and the joint evolution of private physical capital, productivity, and incentives to save.

The remainder of the paper is organized as follows. Section 2 presents the basic framework, which takes as given the degree of efficiency of public capital. Section 3 derives the balanced growth path and discusses stability conditions. Section 4 endogenizes the efficiency of public capital in infrastructure, by relating it to the stock of infrastructure itself measured in proportion of the private capital stock. Section 5 explores the policy implications of the results and compares them with those obtained in some recent studies. I examine, in particular, how a shift in government spending allocation toward infrastructure, financed by either a cut in unproductive expenditure or an increase in foreign aid, affects equilibrium dynamics. This exercise is therefore consistent with the Big Push view referred to earlier. In addition, I consider the case where the government implements a budget-neutral shift in outlays toward health. The final section offers some concluding remarks.

\footnotetext{
${ }^{3}$ By and large, however, mainstream economists have not followed this lead. In their analysis of the historical causes of African underdevelopment, Bertocchi and Canova (2002) for instance barely mention this aspect of colonization.
} 


\section{The Basic Framework}

The economy that I consider is closed and populated by a single, infinitelylived household-producer (or household, for short). It produces a single traded commodity, which can be used for either consumption or investment. With the resources provided by a tax on output, the government invests in infrastructure and spends on commodities, which are used to produce (when combined with public capital in infrastructure) health services. It also spends on "unproductive" activities - that is, activities that have no direct effect on the supply of infrastructure or health services. Both categories of services are assumed to be nonrival and nonexcludable.

\subsection{Production of Commodities}

Commodities, in quantity $Y$, are produced with private capital, $K_{P}$, public capital in infrastructure capital, $K_{I}$, and "effective" labor, defined as the product of the quantity of labor and a productivity index. In turn, productivity depends solely on the available supply of health services, $H$, with a strict proportionality relationship. ${ }^{4}$ Because the growth rate of the population is zero and population size is normalized to unity, effective labor is simply $H$.

Assuming a Cobb-Douglas technology yields ${ }^{5}$

$$
Y=\left(\theta K_{I}\right)^{\alpha} H^{\beta} K_{P}^{1-\alpha-\beta}=\left(\frac{\theta K_{I}}{K_{P}}\right)^{\alpha}\left(\frac{H}{K_{P}}\right)^{\beta} K_{P},
$$

\footnotetext{
${ }^{4}$ It could be assumed that productivity depends not only on access to health services but also directly on infrastructure as well. Better roads, for instance, allow an easier commute to work, thereby reducing stress associated with traffic jams. This effect of infrastructure on productivity could also be subject to nonlinearities similar to those related to the production of commodities, as discussed later.

${ }^{5}$ In what follows, time subscripts are omitted for simplicity. Also, $\dot{x} \equiv d x / d t$ is used to denote the time derivative of any variable $x$.
} 
where $\alpha, \beta \in(0,1)$ and $\theta>0$ is an efficiency parameter which I take as constant for the moment. Thus, production of commodities exhibits constant returns to scale in all factors. ${ }^{6}$ For simplicity, the flow of services provided by each capital stock is taken to be directly proportional to the available stock.

\subsection{Production of Health Services}

As discussed in the introduction, public infrastructure in this economy improves health outcomes, by providing for instance greater access to drinking water or by facilitating garbage disposal through sewage systems. Specifically, I assume that production of health services requires combining government spending on health, $G_{H}$, and public capital in infrastructure. Assuming also a Cobb-Douglas technology yields

$$
H=K_{I}^{\mu} G_{H}^{1-\mu}
$$

where $\mu \in(0,1)$. The provision of health services takes place therefore under constant returns to scale in $K_{I}$ and $G_{H}$. In line with the evidence for many poor countries, only the government provides health services.

\subsection{Household}

The household maximizes the discounted present value of utility:

$$
\max _{C} V=\int_{0}^{\infty} \ln C \exp (-\rho t) d t,
$$

\footnotetext{
${ }^{6}$ See Eicher and Turnovsky (1999) for a discussion of the relation between the existence of a balanced growth path and the assumption of constant returns to scale in endogenous growth models. Note that the aggregate function (1) does not imply diminishing returns to scale at the level of the individual firm. Indeed, as discussed in detail in Agénor (2009a), it can be derived by assuming constant returns to scale with respect to private factors at the firm level, and an externality (or congestion effect) measured in terms of the ratio of the public capital stock to the aggregate private capital stock. In that case, however, public capital is nonexcludable but partially rival.
} 
where $C$ is consumption and $\rho>0$ the subjective discount rate. For simplicity, I assume that the instantaneous utility function is logarithmic in consumption only. A more general specification would be to assume, as in Agénor (2008) for instance, that utility is non-separable in consumption and health services, that is

$$
u(C, H)=\frac{\left(C H^{\kappa}\right)^{1-1 / \sigma}}{1-1 / \sigma}, \quad \sigma \neq 1, \kappa>0
$$

where $\sigma$ is the intertemporal elasticity of intertemporal substitution and $\kappa$ measures the relative contribution of health to utility. However, as can be inferred from the results in the papers cited above, this specification would simply complicate derivations and would not add much to the discussion as long as $\sigma<1$ - the empirically relevant case for developing countries, as documented in a variety of studies (see Agénor and Montiel (2008)). For the purpose at hand - and given my focus on growth, rather than welfare - the logarithmic specification is simpler and I shall retain it throughout. ${ }^{7}$

The rate of time preference is assumed to depend negatively on consumption of health services, and positively on the stock of private capital:

$$
\rho=\rho\left(H, K_{P}\right)
$$

with $\rho_{H}<0$, and $\rho_{K_{P}}>0$.

This specification differs in significant ways from the formulation first proposed by Uzawa (1968), who introduced the idea of a relation between the rate of time preference and consumption. ${ }^{8}$ In the present case, it is health

\footnotetext{
${ }^{7}$ Note also that, as discussed by Cazzavillan (1996) and Chen (2006), if government spending exerts positive externalities on household preferences (in the form of increasing returns to public expenditure in utility), multiple equilibria and indeterminacy may also emerge.

${ }^{8}$ More specifically, Uzawa (1968, p. 489) assumed that the change in the rate of time preference at time $t$ is a positive function of the level of utility at time $t$. Subsequently, in
} 
services, not consumption of goods or commodities, that affect the degree of impatience. The essential motivation here is that healthier individuals are less myopic and tend to value the future more. This can be viewed as a way to capture, in a representative agent model with infinite horizon, the "life expectancy" effect typically emphasized in OLG models with endogenous lifetimes (or mortality rates), as in the original contributions of Blanchard (1985), which builds on Yaari (1965) and Buiter (1988), or more recently in Aísa and Pueyo (2006), where the flow of government expenditure is taken to affect the instantaneous probability of death. ${ }^{9}$ This specification is also consistent with the evidence that poor people tend to have a relatively high rate of time preference, as documented for instance by Lawrance (1991), if one takes a further step and assumes that consumption of health services is positively related to income. ${ }^{10}$

Moreover, I also assume that the rate of time preference is increasing in wealth-or equivalently, here, given that there are no other (private) stores of value in this economy, the stock of private physical capital. As discussed by Mohsin (2004) and Kam (2005) in a different context, this link avoids some of the difficulties posed by Uzawa preferences. ${ }^{11}$ For tractability, I will

their taxonomy of intertemporal utility functions, Shi and Epstein (1993, p. 62) characterized Uzawa preferences as consisting of a relation between the rate of time preference and (current and past) consumption levels.

${ }^{9}$ See also Blackburn and Cipriani (2002), Chakraborty (2004), Bunzel and Qiao (2005), and Hashimoto and Tabata (2005). Ehrlich and Kim (2005) endogenized the mortality rate by assuming instead that the survival probability of individuals depends on consumption.

${ }^{10}$ See Frederick, Loewenstein, and O'Donoghue (2002) for a review of the microeconomic evidence linking discount rates and health outcomes.

${ }^{11}$ In a standard model of optimal saving, Uzawa preferences require increasing marginal impatience for stability; see for instance Epstein and Hynes (1983), and Obstfeld (1990) for an intuitive diagrammatic exposition. The plausibility of increasing marginal impatience has been questioned by many; Blanchard and Fischer (1989, p. 75$)$ went as far as to recommend avoiding the Uzawa specification because "...with its assumption [that the richer are more impatient than the poor, it] is not particularly attractive as a description of preferences." 
assume that $\rho$ can be specified as a function of the ratio of $H$ over $K_{P}$, so that

$$
\rho=\rho\left(\frac{H}{K_{P}}\right)
$$

with $\rho^{\prime}<0$ and $\rho^{\prime \prime}>0$.

The household's resource constraint takes the simple form

$$
\dot{K}_{P}=(1-\tau) Y-C,
$$

where $\tau \in(0,1)$ is the tax rate on income. For simplicity, I assume that private capital does not depreciate.

The household takes the rate of time preference, the tax rate, and the efficiency parameter as given when choosing the optimal time profile of consumption. Using (1) and (6), the current-value Hamiltonian for problem (3) can be written as

$$
L=\ln C+\lambda[(1-\tau) Y-C],
$$

where $\lambda$ is the costate variable associated with constraint (6). From the firstorder condition $d L / d C=0$ and the costate condition $\dot{\lambda}=-d L / d K_{P}+\rho \lambda$, optimality conditions for this problem take the familiar form

$$
\begin{gathered}
1 / C=\lambda, \\
\dot{\lambda}=\lambda\left[\rho\left(\frac{H}{K_{P}}\right)-\frac{s Y}{K_{P}}\right],
\end{gathered}
$$

where $s \equiv(1-\tau) \eta$, with $\eta \equiv 1-\alpha-\beta$, together with the budget constraint (6) and the transversality condition

$$
\lim _{t \rightarrow \infty} \lambda K_{P} \exp (-\rho t)=0
$$




\subsection{Government}

The government invests in infrastructure capital, $G_{I}$, spends on health, $G_{H}$, and on unproductive activities, $G_{U}$. It also collects a proportional $\operatorname{tax} \tau$ on output. If fiscal deficits are precluded, the government budget constraint is given by

$$
G_{I}+G_{H}+G_{U}=\tau Y .
$$

Spending components are all taken to be fixed fractions of tax revenues:

$$
G_{h}=v_{h} \tau Y, \quad h=I, H, U
$$

where $v_{h} \in(0,1)$. The fixity of spending shares is justified by the fact that the goal here is to provide a positive, rather than normative, theory of growth and development.

Combining (10) and (11), the government budget constraint can be rewritten as

$$
v_{I}+v_{H}+v_{U}=1 .
$$

The stock of public capital in infrastructure evolves over time according to

$$
\dot{K}_{I}=\varphi G_{I},
$$

where $\varphi \in(0,1)$ is an efficiency parameter that measures the extent to which investment flows translate into actual accumulation of public capital. The case $\varphi<1$ reflects the view that investment spending on infrastructure is subject to inefficiencies, which tend to limit their positive impact on the public capital stock. Arestoff and Hurlin (2005) and Hurlin (2006), for instance, estimate the value of $\varphi$ to vary between 0.4 and 0.6 for developing countries. As it turns out, this parameter (which can broadly be thought of as an indicator of the quality of public sector management, or governance) 
plays an important role in discussing the role of public policies in escaping from a low-growth trap. ${ }^{12}$ For simplicity, public capital is assumed not to depreciate.

Combining (6), (10), and (13) yields the equilibrium condition of the market for commodities:

$$
Y=C+\left(\dot{K}_{P}+\dot{K}_{I}\right)+G_{H}+G_{U}
$$

\section{Constant Efficiency}

I first study the properties of the model with a constant efficiency parameter, $\theta$. In the present setting, a competitive equilibrium can be defined as follows:

Definition 1. A competitive equilibrium is a set of infinite sequences for the allocations $\left\{C, K_{P}, K_{I}\right\}_{t=0}^{\infty}$, such that $\left\{C, K_{P}\right\}_{t=0}^{\infty}$ satisfy equations (7), (8), and (9), the path $\left\{H, K_{P}, K_{I}\right\}_{t=0}^{\infty}$ satisfies equations (2), (6), and (14), for given values of the tax rate, $\tau$, the spending shares, $v_{I}, v_{H}$, and $v_{U}$, and the efficiency parameter, $\theta$.

From equation (7),

$$
\dot{C} / C=-\dot{\lambda} / \lambda
$$

whereas, from (11) and (13),

$$
\frac{\dot{K}_{I}}{K_{I}}=\varphi v_{I} \tau\left(\frac{Y}{K_{I}}\right)=\varphi v_{I} \tau k_{I}^{-1}\left(\frac{Y}{K_{P}}\right),
$$

where $k_{I}=K_{I} / K_{P}$. From (1), (2), and (11),

$$
Y=\left(\theta k_{I}\right)^{\alpha}\left(\frac{K_{I}^{\mu} G_{H}^{1-\mu}}{K_{P}}\right)^{\beta} K_{P}=\theta^{\alpha} k_{I}^{\alpha+\mu \beta}\left(v_{H} \tau\right)^{(1-\mu) \beta}\left(\frac{Y}{K_{P}}\right)^{(1-\mu) \beta} K_{P} .
$$

\footnotetext{
${ }^{12}$ Total unproductive spending includes not only $G_{U}$ but also the "efficiency loss" in productive spending, $(1-\varphi) G_{I}$. An interesting avenue to explore would be to endogenize $\varphi$, by linking it to the degree of corruption or political incentives (see, for instance, Robinson and Torvik (2005)). However, this is well beyond the scope of this paper.
} 
This expression can be rewritten as

$$
\frac{Y}{K_{P}}=\left(v_{H} \tau\right)^{(1-\mu) \beta / \Omega} \theta^{\alpha / \Omega} k_{I}^{(\alpha+\mu \beta) / \Omega},
$$

where $\Omega \equiv 1-(1-\mu) \beta>0$, so that $\alpha / \Omega<1$.

Combining this result with (16) yields

$$
\frac{\dot{K}_{I}}{K_{I}}=\varphi v_{I} \tau^{1 / \Omega} v_{H}^{(1-\mu) \beta / \Omega} \theta^{\alpha / \Omega} k_{I}^{-\eta / \Omega}
$$

Substituting (1) and (17) in the household budget constraint (6) yields

$$
\frac{\dot{K}_{P}}{K_{P}}=(1-\tau)\left(v_{H} \tau\right)^{(1-\mu) \beta / \Omega} \theta^{\alpha / \Omega} k_{I}^{(\alpha+\mu \beta) / \Omega}-c,
$$

where $c=C / K_{P}$.

Using (2), the health-private capital ratio, denoted $h$, is given by

$$
h=\left(\frac{H}{K_{I}}\right)\left(\frac{K_{I}}{K_{P}}\right)=\left(\frac{G_{H}}{K_{I}}\right)^{1-\mu} k_{I}=\left(\frac{G_{H}}{K_{P}}\right)^{1-\mu} k_{I}^{\mu},
$$

that is, using (11) and (17),

$$
h=\left(v_{H} \tau\right)^{1-\mu}\left[\left(v_{H} \tau\right)^{(1-\mu) \beta / \Omega} \theta^{\alpha / \Omega} k_{I}^{(\alpha+\mu \beta) / \Omega}\right]^{1-\mu} k_{I}^{\mu},
$$

so that

$$
h=\left(v_{H} \tau\right)^{(1-\mu) / \Omega} \theta^{\alpha(1-\mu) / \Omega} k_{I}^{\Phi / \Omega},
$$

where $\Phi \equiv \mu+\alpha(1-\mu)>0$.

Substituting this result in (5) yields

$$
\rho=\chi\left(k_{I} ; \theta\right)
$$

with $\chi_{k_{I}} \equiv \rho^{\prime} \Phi \tilde{h} / \Omega \tilde{k}_{I}<0$ and $\chi_{\theta} \equiv \rho^{\prime} \alpha(1-\mu) \tilde{h} / \theta \Omega<0$.

Substituting (8) in (15) yields $\dot{C} / C=s\left(Y / K_{P}\right)-\rho$, that is, using (17) and (21),

$$
\frac{\dot{C}}{C}=s\left(v_{H} \tau\right)^{(1-\mu) \beta / \Omega} \theta^{\alpha / \Omega} k_{I}^{(\alpha+\mu \beta) / \Omega}-\chi\left(k_{I} ; \theta\right) .
$$


Equations (18), (19), and (22) can be further condensed into a first-order nonlinear differential equation system in $c=C / K_{P}$ and $k_{I}=K_{I} / K_{P}$ :

$$
\begin{gathered}
\frac{\dot{c}}{c}=\xi k_{I}^{(\alpha+\mu \beta) / \Omega}-\chi\left(k_{I} ; \theta\right)+c \\
\frac{\dot{k}_{I}}{k_{I}}=v_{H}{ }^{(1-\mu) \beta / \Omega} \theta^{\alpha / \Omega}\left\{\varphi v_{I} \tau^{1 / \Omega} k_{I}^{-\eta / \Omega}-(1-\tau) \tau^{(1-\mu) \beta / \Omega} k_{I}^{(\alpha+\mu \beta) / \Omega}\right\}+c
\end{gathered}
$$

where

$$
\xi \equiv-(1-\tau)(\alpha+\beta)\left(v_{H} \tau\right)^{(1-\mu) \beta / \Omega} \theta^{\alpha / \Omega}<0
$$

These two equations, together with an initial condition on $k_{I}$ at $t=0$, and the transversality condition (9), characterize the dynamics of the economy.

The balanced-growth path (BGP) can therefore be defined as follows:

Definition 2. The BGP is a set of sequences $\left\{c, k_{I}\right\}_{t=0}^{\infty}$, constant spending shares, tax rate, and efficiency parameter, satisfying Definition 1, such that for an initial condition $k_{I}=k_{I}^{0}$, equations (23) and (24) and the transversality condition (9) are satisfied, the government budget constraint (12) holds, and consumption, the stocks of private and public capital, all grow at the same constant rate $\gamma$.

By implication, $\gamma$ is also the rate of growth of output of commodities and supply of health services. Using (7), the transversality condition (9) can be rewritten as

$$
\lim _{t \rightarrow \infty} c^{-1} \exp (-\rho t)=0,
$$

which is also satisfied, because $c$ is constant along the BGP.

Based on the results in the Appendix, the following proposition can be established:

Proposition 1. With a constant degree of efficiency of public infrastructure, the BGP is unique and locally determinate. A high degree of sensitivity of the rate of time preference with respect to the health-private capital ratio enhances stability. 
From (18) and (22), the steady-state growth rate $\gamma$ is given by the equivalent forms

$$
\begin{gathered}
\gamma=\varphi v_{I} \tau^{1 / \Omega} v_{H}{ }^{(1-\mu) \beta / \Omega} \theta^{\alpha / \Omega} \tilde{k}_{I}^{-\eta / \Omega}, \\
\gamma=s\left(v_{H} \tau\right)^{(1-\mu) \beta / \Omega} \theta^{\alpha / \Omega} \tilde{k}_{I}^{(\alpha+\mu \beta) / \Omega}-\chi\left(\tilde{k}_{I} ; \theta\right),
\end{gathered}
$$

where $\tilde{x}$ denotes the stationary value of $x \cdot{ }^{13}$

Adjustment toward the long-run equilibrium is illustrated in Figure 1, using linearized versions of (23) and (24). Line $K K$ corresponds to combinations of $\left(c, k_{I}\right)$ for which $\dot{k}_{I}=0$, whereas line $C C$ corresponds to combinations of $\left(c, k_{I}\right)$ for which $\dot{c}=0$. Both lines are upward-sloping and saddlepath stability requires $K K$ to cut $C C$ from below. The saddlepath, $S S$, also has a positive slope. The long-run equilibrium obtains at point $E$.

To briefly illustrate the functioning of the model - and with an eye to the Big Push policy recommendation discussed later on - consider an unexpected, budget-neutral increase in the share of spending on infrastructure, $v_{I}$, offset by a reduction in unproductive expenditure (that is, $\left.d v_{I}=-d v_{U}\right) \cdot{ }^{14}$ Based on the results in the Appendix, as well as equations (27) and (28), the following proposition can be established:

Proposition 2. An unexpected, permanent increase in the share of investment in infrastructure, financed by a cut in unproductive expenditure $\left(d v_{I}=-d v_{U}\right)$, raises the steady-state growth rate as well as the steady-state values of the consumption-private capital ratio and the public-private capital ratio.

\footnotetext{
${ }^{13}$ Equation (28) implies that for the steady state to be characterized by positive growth, the discount rate cannot be too sensitive to the health-capital ratio.

${ }^{14}$ See Agénor (2008) for an analysis of budget-neutral shifts in the spending shares $v_{H}$ and $v_{I}$. Growth- and welfare-maximizing spending allocations are also discussed in those papers. Note that here, increases in productive spending shares would not involve a tradeoff per se, if they are offset by cuts in unproductive spending. I will return to this issue later.
} 
A diagrammatic analysis of the adjustment path associated with a budgetneutral shift in spending toward infrastructure is also shown in Figure 1. Such a shift involves only a rightward shift in $K K$ and no change in $C C$. As a result, both the public-private capital ratio and the consumption-private capital ratio are unambiguously higher in the new equilibrium. The adjustment path corresponds to the sequence $E A E^{\prime}$. Consumption (which is here a perfect substitute to physical capital formation) jumps upward on impact and continues to rise over time.

Intuitively, the positive long-run effect on permanent income associated with the increase in government investment in infrastructure leads to an immediate increase in consumption. However, output is given on impact, because neither one of the capital stocks can change instantaneously. The economy's resource constraint (14) implies therefore that the jump in consumption and the rise in public investment (that is, $\dot{K}_{I}(0)>0$ ) must be accompanied by a fall in private investment on impact, that is, $\dot{K}_{P}(0)<0$. Consequently, the public-private capital ratio rises unambiguously on impact $\left(\dot{k}_{I}(0)>0\right)$.

Over time, the transitional dynamics of the public-private capital ratio and the growth rate of output are driven by the marginal physical product of private capital, which in turn depends on the stock of public capital in infrastructure. This dependence is both direct and indirect - given the assumed shape of the production function for health services, the effective supply of labor depends on the stock of infrastructure capital as well. When the share of government investment (and thus the level of investment itself) increases, and the stock of public capital expands, that product rises at first and growth will tend to be high. Agents will be investing more, causing physical capital to be accumulated more rapidly and the growth rate to rise initially. Thus, 
the rate of private capital accumulation follows a nonmonotonic process: after falling at first (to accommodate the initial increase in consumption and public investment, as noted earlier), it begins to rise, to reflect a greater rate of return on physical assets.

But because the marginal product of private capital is negatively related to the stock of private capital itself (given diminishing marginal returns to all inputs), private investment will tend to fall over time as more of that type of capital is accumulated. The transition to the steady-state growth rate will be therefore characterized by a relatively high growth rate of private capital and output initially, followed by a slowdown in both variables that may vary in speed - depending on how quickly decreasing returns settle in. The increase in private capital falls nevertheless short of the rate of accumulation of public infrastructure assets, implying that the public-private capital ratio rises continuously over time. In turn, the increase in that ratio tends to raise production of health services (measured in proportion to the private capital stock) and therefore to reduce preference for the present. The greater the sensitivity of the discount rate to health, the greater will be the incentive to shift resources toward the future, and the higher will be the rates of private capital accumulation and output growth. During the transition, nonetheless, the consumption-private capital ratio increases continuously, implying that consumption rises at a faster rate than private capital. The increase in savings needed to finance private capital accumulation is brought about by an increase in output, whose growth rate must therefore exceed the growth rate of consumption and public investment.

Rather than performing a detailed investigation of how stability is affected by the various structural parameters of the model, I now turn to the main focus of the paper - the existence of network externalities associated with 
public infrastructure, and the extent to which the nonlinearities that they entail with respect to the degree of efficiency of public capital may lead to multiple equilibria.

\section{Network Externalities and Efficiency}

I now consider the case where the efficiency of public capital, $\theta$, is endogenously related to the stock of public infrastructure itself through a convexconcave function. This specification aims to capture the existence of network effects, discussed in the introduction - the idea that the stock of public infrastructure must be sufficiently large for efficiency effects to kick in. At the same time, while it may be highly beneficial to build up a network of, say, roads, the efficiency gains from expanding or improving the network may not subsequently be as high. Moreover, congestion effects may kick in beyond a certain point, even if the stock of public capital continues to expand. Indeed, if some portion of public capital is rival, the critical mass that generates network externalities would depend in part on the level of private production. To capture these effects-albeit in a highly stylized manner-I assume as in Futagami and Mino (1995) that threshold levels depend on the ratio of public infrastructure assets to private capital. ${ }^{15}$

Formally, the efficiency function is taken to be given by

$$
\theta=\left\{\begin{array}{l}
\theta_{L} \text { for } k_{I}<k_{I}^{L}, \\
\theta_{M}\left(k_{I}\right) \text { for } k_{I}^{L} \leq k_{I}<k_{I}^{H}, \\
\theta_{H}\left(k_{I}\right) \text { for } k_{I} \geq k_{I}^{H},
\end{array}\right.
$$

where $\theta_{M}^{\prime}, \theta_{M}^{\prime \prime}>0$, whereas $\theta_{H}^{\prime}>0$ and $\theta_{H}^{\prime \prime}<0$. I also assume that

\footnotetext{
${ }^{15}$ Note that in Futagami and Mino (1995), it is the efficiency of private capital that takes a convex-concave shape, whereas the focus here is on the efficiency of public capital itself.
} 
$\lim _{k_{I} \rightarrow \infty} \theta_{H}\left(k_{I}\right)=\theta_{H}$, where $\theta_{H}>\theta_{L}{ }^{16}$ Thus, the efficiency function is constant over the interval $\left(0, k_{I}^{L}\right)$, convex over the interval $\left(k_{I}^{L}, k_{I}^{H}\right)$, and concave over the interval $\left(k_{I}^{H}, \infty[\right.$. This is depicted in Figure 2, where point $B$ corresponds to $\theta_{M}^{\prime \prime}\left(k_{I}^{H}\right)=\theta_{H}^{\prime \prime}\left(k_{I}^{H}\right)=0$. Put differently, over the interval $\left(k_{I}^{L}, \infty[\right.$, the efficiency function has a logistic shape.

I assume, as was done earlier, that the household takes $\theta$ as given when optimizing. Proceeding as before (that is, with the linearized system), and using the results in the Appendix, the following proposition can be established:

Proposition 3. Suppose that the degree of efficiency of public infrastructure is subject to threshold effects, as described in (29). Depending on the strength of the efficiency externality, and other model parameters, there may be either no equilibrium, one equilibrium, or multiple equilibria.

Figures 3 and 4 illustrate the cases of zero and one equilibrium, under the assumption that the efficiency externality is strong enough to ensure that both $C C$ and $K K$ have a steeper slope in the interval $\left(k_{I}^{L}, k_{I}^{H}\right)$. In both figures, $G$ and $G^{\prime}$ correspond to the points at which externalities kick in. In Figure 3, point $E$ corresponds to the point where $C C$ and $K K$ would have intersected with $\theta$ constant; but because this point is located to the right of the threshold level of the public-private capital ratio $k_{I}^{L}$, it cannot be reached. After point $G$, and during the whole interval $\left(k_{I}^{L}, k_{I}^{H}\right)$, both $C C$ and $K K$ have a steeper slope, because both depend on $\theta$. Once the public-private capital stock reaches $k_{I}^{H}$, both slopes become less steep. But they never intersect - although the slope of $K K$ may be steeper than $C C$ during the range of increasing returns (as shown in the figure), they would

\footnotetext{
${ }^{16}$ Although I do not elaborate in this paper on the determinants of $\theta_{L}$, it should be noted that inadequate and weak institutions may translate into poor efficiency of public capital in infrastructure, just like it may affect the efficiency of public investment, $\varphi$ (as discussed again later).
} 
have intersected at a value higher than $k_{I}^{H}$; decreasing returns in efficiency beyond that threshold value prevents this from happening. Beyond point $G^{\prime}$, curve $C C$ is shown as steeper than $K K$, but no equilibrium can be achieved: as long as the slope of $K K$ is flatter than (or, at most, equal to) the slope of $C C$, the two curves cannot intersect.

Figure 4 considers, instead, the case where a unique equilibrium may occur. There are two cases to consider. In the upper panel, curves $C C$ and $K K$ intersect before the threshold level $k_{I}^{L}$ is reached; the steady-state equilibrium obtained at point $E$ is unique, and any initial capital ratio $k_{I}^{0}$ that differs from $\tilde{k}_{I}$ will converge toward that value along the saddlepath. In a sense, network externalities are powerless to lead the economy away from point $E$, which will be referred to as the "low growth" equilibrium. Put differently, because this is the only stable equilibrium, the economy stagnates. Moreover, because poor infrastructure leads to low output of health services, which in turn hampers labor productivity and reduces incentives to save, this low-growth equilibrium can be equally characterized as a "low productivitylow savings" trap. ${ }^{17}$ In the lower panel, curves $C C$ and $K K$ intersect beyond $k_{I}^{L}$, that is, after increasing returns in efficiency start kicking in. As shown in the figure, $K K$ cuts $C C$ from below - as required for saddlepath stability (see Figure 1). Moreover, the lines intersect only once, because the range of increasing returns in efficiency is sufficiently large to ensure that, once decreasing returns set in (beyond $G^{\prime}$ ), and both slopes become less steep again, they cannot intersect once more (in the figure, $K K$ remains steeper than $C C$ beyond $k_{I}^{H}$ as well). In what follows, the equilibrium at point $E$

\footnotetext{
${ }^{17}$ This view is not inconsistent with Dasgupta's (1999) emphasis on poor health generating a low-growth trap through the mechanism of poor health making workers unproductive, and the resulting low incomes reinforcing poor health; see also Sala-i-Martin (2005). Azariadis (2006) offers a broader discussion of poverty traps.
} 
will be referred to as the "moderate growth" equilibrium.

Consider now the case where multiple equilibria exist. From the results of the Appendix, the following proposition can be established:

Proposition 4. Suppose that the degree of efficiency of public infrastructure is subject to threshold effects, as described in (29). If the efficiency externality is sufficiently strong, there may be three equilibria. The two extreme steady states are saddlepoint stable, whereas the intermediate steady state is unstable.

Figures 5 and 6 illustrate the dynamics in this case. ${ }^{18}$ The three equilibria are labeled $E^{1}, E^{2}$, and $E^{3}$, with corresponding notation for the steady-state values of $c$ and $k_{I}$. As shown in Figure 5, for an economy starting to the left of $E^{1}$, or to the right of $E^{1}$ before point $G$ (that is, for $\tilde{k}_{I}^{1}<k_{I}^{0}<k_{I}^{L}$ ), as well as to the right of $E^{3}$, or to the left of $E^{3}$ after point $G^{\prime}$ (that is, for $k_{I}^{H}<k_{I}^{0}<\tilde{k}_{I}^{3}$ ) the realization of a particular equilibrium depends entirely upon history - that is, the initial value $k_{I}^{0}$. For instance, an economy whose initial level of public infrastructure is relatively low, $k_{I}^{0}<\tilde{k}_{I}^{1}$, only the lowgrowth equilibrium $E^{1}$ can be attained, whereas an economy whose initial stock of capital is $k_{I}^{0}>\tilde{k}_{I}^{3}$, but with otherwise identical characteristics, will eventually reach the high-growth equilibrium $E^{3}$. In both cases, $K K$ cuts $C C$ from below, ensuring saddlepath stability.

If the initial public-private capital ratio lies between $k_{I}^{L}$ and $k_{I}^{H}$, as shown in Figure 6, several ranges can be distinguished. Let $k_{C}^{1}$ and $k_{C}^{2}$ be defined as threshold levels that are such that $k_{I}^{L}<k_{C}^{1}<k_{C}^{2}<k_{I}^{H}$, with $\left|k_{I}^{L}-k_{C}^{1}\right|$ and $\left|k_{I}^{H}-k_{C}^{2}\right|$ arbitrarily small. Standard (local) dynamic analysis suggests therefore that the interval $\left(k_{C}^{1}, k_{C}^{2}\right)$, which corresponds to points $J$ and $J^{\prime}$ on the saddlepaths leading to $E^{1}$ and $E^{3}$, respectively, and which includes the

\footnotetext{
${ }^{18}$ In principle, it is possible for the model to generate also two equilibria, one stable and one unstable. However, this is rather unlikely, as suggested by the discussion in the Appendix.
} 
unstable equilibrium $E^{2}$, defines a zone of indeterminacy. Paths originating in the interval $\left(k_{I}^{L}, k_{C}^{1}\right)$ would tend to converge to the low productivity-low savings trap, $E^{1}$, whereas paths originating in the interval $\left(k_{C}^{2}, k_{I}^{H}\right)$ would tend to converge to the high-growth equilibrium, $E^{3}$.

By contrast, for any path originating within the interval $\left(k_{C}^{1}, k_{C}^{2}\right)$, the economy could go either way: the initial value of $c$ is indeterminate for $k_{I}^{0}$ given, so there exists an infinite number of perfect foresight equilibrium paths - all of which legitimate in the sense that they do not violate the transversality condition for household's optimization (equation (26)). In that interval, "optimistic" expectations (that is, the belief that the economy can reach the high-growth steady state) could prove self-fulfilling and stir the economy to the high-growth equilibrium; but because nothing ensures that expectations can be coordinated in such a way, "pessimistic" expectations could do as well, and the economy may end up in the low-growth equilibrium. ${ }^{19}$ This is illustrated by the three paths originating from point $E^{2}$, under the assumption that $k_{I}^{0}=\tilde{k}_{I}^{2}{ }^{20}$ Thus, for some initial values $k_{I}^{0}$ of the (predetermined) public-private capital ratio, there could be several equilibrium trajectories - some leading to stagnation, others to high growth. There is therefore a coordination problem, which creates a possible role for public policy - an issue to which I now turn.

\footnotetext{
${ }^{19}$ See Matsuyama (1991) for instance for an analysis of the role of self-fulfilling expectations in the development process.

${ }^{20}$ As for instance in Futagami and Mino (1995), it is possible for closed orbits (or limit cycles) to exist around $E^{2}$. Indeed, the conditions $\operatorname{tr} J=0$ and $\operatorname{det} J>0$, where $J$ is the Jacobian matrix evaluated at $E^{2}$, imply that the system is unstable and has two purely imaginary eigenvalues; this result cannot be excluded a priori. However, this is of little interest in the present context.
} 


\section{The Role of Public Policy}

To illustrate the role of public policy, I first examine the case where, starting from a position of a unique equilibrium (as illustrated in Figure 4) the government implements as before a budget-neutral increase in the share of public investment in total infrastructure, financed by a cut in unproductive expenditure (that is, $d v_{I}+d v_{U}=0$ ). As shown in Figure 7, there are two cases to consider. In the upper panel, as in Figure 4, the initial equilibrium occurs at a value of the public-private capital ratio that is less than the lower threshold level $k_{I}^{L}$. The increase in $v_{I}$, as in Figure 1, shifts line $K K$ only to the right. But if this shift is relatively small, the new $K K$ will still intersect $C C$ to the left of $k_{I}^{L}$, at a point like $E^{\prime}$; although the consumption-capital ratio and the steady-state growth rate eventually increase as a result of the policy shift, the effect is relatively limited because externalities do no kick in. By contrast, if the increase in $v_{I}$ is large enough to shift $K K$ in such a way that the point of intersection with $C C$ occurs to the right of $k_{I}^{L}$, at a point like $E^{\prime \prime}$, the economy will be in the zone of increasing returns associated with the efficiency of public capital, and the increase in the consumption-capital ratio will exceed by an order of magnitude due to the convexity of $\theta$ in that range, which implies that both lines have a steeper slope - what would have been achieved in the absence of network effects. In a manner similar to Figure 1, if the initial equilibrium is at $E$, the adjustment process will take the economy through a point such as $D$ to point $E^{\prime \prime}$.

A similar result obtains in the lower panel of Figure 7, where the initial steady-state position of the economy is at the "moderate growth" equilibrium point located to the right of the lower threshold level $k_{I}^{L}$. If the increase in the share of public investment in infrastructure is not large, the rightward shift 
in $K K$ will lead to a new intersection point with $C C$ located to the left of $k_{I}^{H}$, such as point $E^{\prime}$. A larger shift in $K K$, however, would lead to a steadystate equilibrium such as $E^{\prime \prime}$, located to the right of $k_{I}^{H}$. At that point, the consumption-capital ratio is unambiguously higher than what would obtains at $E^{\prime}$, because $\theta$ remains increasing in $k_{I}$ (albeit at a decreasing rate after $\left.k_{I}^{H}\right)$. The adjustment process will again follow the sequence $E D E^{\prime \prime}$. These results can be summarized in the following proposition:

Proposition 5. If the economy's equilibrium is unique, a large budgetneutral reallocation of government expenditure toward infrastructure investment and away from unproductive spending will shift the economy to a position where it can benefit from the externalities associated with public capital.

Consider now the case where externalities associated with public capital are strong, and multiple equilibria exist. As noted in the previous section, a coordination problem then arises - which one of several possible paths is taken will depend on the ability of private agents to coordinate their actions on the "good" equilibrium. As usual, the problem can be thought of in terms of the tendency for optimistic or pessimistic expectations to become self-fulfilling. In some sense, the problem is one of coordinating beliefs.

The role of public policy in coordinating beliefs is indeed crucial in the present setting because of the interplay between private and public capital accumulation. Suppose that initially the economy is at the low-growth steady state, $E^{1}$. The household takes the stock of public infrastructure as given. Then, there is no incentive to reduce consumption, and engage in capital accumulation, in order to switch to a higher growth path. Stagnation results from the lack of public capital relative to private capital, which itself translates into a low degree of efficiency of public capital, given the existence of network effects. The low growth equilibrium is stable in the sense that small increases in private capital stock will not lead to a jump to the higher growth 
steady state. The reason is that, because public investment is financed by a tax on private output, the supply of public infrastructure is an increasing function of the private capital stock. Moreover, with limited supply of public capital, production of health services is low, and the rate of time preference remains high. Thus, as noted earlier, low savings and labor productivity also characterize the stagnating equilibrium.

Now suppose that, in an attempt to coordinate beliefs, the government implements the same policy shift as above, starting from the low-growth equilibrium point $E^{1}$. As shown in Figure 8, there are two possible outcomes. If the shift in spending translates into a shift in $K K$ that is relatively mild, the two curves will intersect first at a point such as $A$, located to the left of the initial unstable equilibrium $E^{2}$, and again at a point such as $A^{\prime}$ located to the northeast of $E^{3}$. Essentially, the unstable steady state is now "lower" whereas the high-growth stable steady state is higher. Put differently, the policy shift tends to reduce the zone of indeterminacy $\left(k_{C}^{1}, k_{C}^{2}\right)$ while expanding the interval $\left(k_{C}^{2}, k_{I}^{H}\right){ }^{21}$ Although this is not sufficient to ensure that the policy shift will lead necessarily to the high-growth equilibrium (the realization of a particular steady state will continue to depend on history as well as on expectations of private agents in the indeterminacy zones), the reduction in the indeterminacy range increases the likelihood that the economy will select a trajectory that will lead eventually to $E^{3}$.

If the shift in spending translates into a relatively large shift in $K K$ (so much so that the the new curve passes below point $B$ ) the unstable equilibrium point $E^{2}$ disappears entirely, given that $C C$, by construction, is steeper than $K K$ in the interval $\left(k_{I}^{H}, k_{I}^{L}\right)$; only the high-growth equilibrium, point $A^{\prime \prime}$, remains. In that case, if the economy's position is $E^{1}$, the adjustment

\footnotetext{
${ }^{21}$ The change in the interval $\left(k_{I}^{L}, k_{C}^{1}\right)$ is in general unclear.
} 
path is the same as in Figure 1-on impact the consumption-capital ratio will jump from $\tilde{c}^{1}$ to a point such as $D$ located on the saddlepath leading to $A^{\prime \prime}$. These results can be summarized in the following proposition:

Proposition 6. If there are three steady-state equilibria, a budgetneutral reallocation of government expenditure toward infrastructure investment and away from unproductive spending may either reduce the zone of indeterminacy around the unstable steady state $E^{2}$ or entirely eliminate it, thereby increasing the likelihood that the economy will achieve the high-growth steady state.

In the foregoing discussion, the increase in the share of public expenditure on infrastructure was assumed to be offset by a cut in unproductive spending. Given the amount of waste that often characterizes public spending in developing countries, this is not an unreasonable assumption. But a more general interpretation is also possible, by assuming $G_{U}<0$ and by defining $-G_{U}$ as foreign aid (that is, grants). Thus, the analysis provides a theoretical rationale for those who have advocated development strategies based on large increases in public investment in infrastructure financed by foreign aid - as for instance in some recent international reports on external assistance to low-income countries, such as the Millennium Project (2005) of the United Nations.

My analysis, however, offers a note of caution. In the model, the ability of a shift in the share of public spending on infrastructure to guide the economy toward a high growth path is predicated on two critical parameters - the elasticity of output with respect to public infrastructure, $\alpha$, which determines the effect of the public capital stock on the marginal product of private capital; and the degree of efficiency of public investment, $\varphi$, which, as noted earlier, can be viewed as a broad indicator of the quality of governance. The lower the values of these two coefficients, the larger the increase in public 
investment in infrastructure will need to be to generate the shift in $K K$ alluded to earlier. The role of $\varphi$ is particularly important; weak governance is often viewed as a chief culprit when assessing why public expenditure often fails to achieve its intended outcomes. ${ }^{22}$ Moreover, a negative correlation could exist between aid and the efficiency parameter $\varphi$, if indeed, as found by Svensson (2000), aid increases corruption in ethnically divided societies. This can be stated in the form of the following corollary to the above propositions:

Corollary to Propositions 5 and 6. A large shift in government expenditure toward infrastructure will generate desirable effects only if the degree of efficiency of public investment, $\varphi$, is sufficiently high.

A Big Push policy may therefore require concomitant measures to improve governance. Of course, despite past evidence, aid programs themselves could be structured so as to bring about an increase in efficiency of public investment - by changing for instance the nature of conditionality in these programs and making it performance-based, rather than policy-based, and by allocating a sufficient fraction of aid to capacity building and institutional reform. If efficiency and governance can indeed be made to depend on aid itself, the argument for a Big Push in infrastructure investment financed by external assistance would be strengthened.

Finally, one may ask if results similar to those associated with a shift in government spending toward infrastructure investment could not be achieved instead by a shift toward health expenditure, again financed by a cut in unproductive outlays or foreign aid. After all, spending on health is also directly productive in this economy, and health services have a direct positive effect on savings. If the degree of efficiency of investment, $\varphi$, is low, and

\footnotetext{
${ }^{22}$ There is no shortage of anecdotal evidence for this in the development literature. It is also confirmed by a number of recent studies, which show that corruption distorts incentives to allocate public investment to its initial purpose.
} 
the direct effect of public infrastructure on output is somewhat limited, the economy may well be better off by spending more on health. However, health services do not generate externalities in the present framework; moreover, their production requires also infrastructure services. If the parameter $\mu$ (the elasticity of output of health services with respect to infrastructure) is relatively large, as suggested by some of the recent studies reviewed in Agénor (2009b), a strategy based exclusively on the expansion of health services may not be sufficient to help an economy move to a higher growth path. Of course, this conjecture is predicated in part on the way health services are modeled in the present setting. If, for instance, health services are assumed to generate large positive externalities on labor productivity (with strong convex effects initially) a case for a "health first" strategy could in principle be viable. The issue then becomes an empirical one.

\section{Concluding Remarks}

The purpose of this paper has been to propose a theory of long-run development based on public infrastructure as the main engine of growth. In addition to investing in infrastructure, the government spends on health services, which raise labor productivity and lower preference for the present. The rate of time preference is modeled as a decreasing function of health services, relative to the stock of private capital. Agents become less impatient as their health improves; this, in turn, raises savings and stimulates growth. In addition, infrastructure affects the production of both commodities and health services, and therefore labor efficiency.

The first part of the paper described the model and illustrated its functioning by considering a budget-neutral shift in public spending toward in- 
vestment in infrastructure. This reallocation was shown to raise the steadystate value of health production, thereby lowering the rate of time preference and raising savings. This additional savings translates into higher private capital and consumption in the steady state. Indeed, in the model it is not only increases in the rate of return on physical capital that leads households to save more, but also improvements in the consumption of health services - the supply of which depends on the availability of public capital in infrastructure. Although the model does not explicitly account for demographic factors, its prediction that low growth tends to be associated with low consumption of health services and poor productivity is consistent with several studies suggesting that health improvements tend to have a large impact on growth. Fogel $(1994,1997)$ for instance, argued that a significant fraction of economic growth in Britain during the period 1780-1980 (about 0.33 percent per annum) was due to an increase in effective labor inputs that resulted from workers' better nutrition and improved health. ${ }^{23}$ In the same vein, Sohn (2000) found that improved nutrition increased available labor inputs in South Korea by 1 percent a year or more during 1962-95. A number of other studies have shown that initial levels of life expectancy tend to have a significant effect on subsequent growth rates (see Agénor (2009a)). In particular, Lorentzen, McMillan and Wacziarg (2008) found that countries with a high rate of adult mortality tend to experience low rates of growthpossibly because when people expect to die relatively young, they have less incentives to save and invest in the acquisition of skills. ${ }^{24}$ What the model

\footnotetext{
${ }^{23}$ Boucekkine et al. (2003) estimate that a steady decline in adult mortality (while child mortality stayed level) accounts for 70 percent of the growth acceleration that modern Europe experienced between 1700 and 1820.

${ }^{24}$ They also found that the estimated effect of high adult mortality on growth is large enough to explain Africa's poor economic performance between 1960 and 2000. Indeed, in the 40 countries with the highest adult mortality rates in their sample of 98 countries, all
} 
adds to these studies is that infrastructure may well be one of the main engines behind the improvement in health outcomes.

In the second part of the paper, it was argued that, as a result of network effects, public infrastructure may generate strong nonconvexity of the economy's production technology, with important consequences for the relationship between public capital and economic growth. As a result of these effects, the degree of efficiency of public infrastructure becomes nonlinearly related to the stock of public capital (relative to the private capital stock) itself. It was shown that, as a result of these nonlinearities, there may be no equilibrium, a unique equilibrium, or multiple equilibria.

The third part of the paper focused on the role of public policy. It was shown that if there are three steady-state equilibria, a budget-neutral shift toward infrastructure investment and away from unproductive spending (or financed by foreign aid) may either reduce the zone of indeterminacy around the unstable steady state or entirely eliminate it - if it is large enough. However, the analysis suggests some caution in the Big Push view recently revived by Sachs (2005), among others. Sachs emphasizes the lack of savings at low levels of income as the main cause of a poverty trap. ${ }^{25}$ This paper suggests that his analysis is incomplete. In particular, in the present paper a large shift toward spending on infrastructure will generate desirable effects only if the degree of efficiency of public investment is sufficiently high. A Big Push policy may therefore require concomitant measures to improve governancepossibly by changing the nature and focus of aid conditionality.

The analysis can be extended in several directions. First, greater access to are in Sub-Saharan Africa, except three.

${ }^{25} \mathrm{He}$ also discussed increasing returns (or threshold effects) associated with the capital stock, but without an explicit formal analysis focusing on public infrastructure, as was done in the present paper. 
health services enhances not only workers' productivity, but also the ability to learn and accumulate human capital - a significant constraint to growth in many low-income countries. ${ }^{26}$ It would therefore be useful to introduce human capital accumulation and consider its interactions with health. Much recent evidence suggests that causality goes both ways, as documented for instance by Agénor (2009b). On the one hand, higher life expectancy increases the payoff from investment in education, thereby raising incentives to invest in the acquisition of skills. Evidence along these lines (in the form of a significant effect of life expectancy on years of schooling) is provided by Acemoglu and Johnson (2007). On the other, a higher level of education tends to improve health outcomes, in part because it increases awareness of diseases, both to the individual and their family members (such as mothers teaching their children to wash their hands before preparing and eating food). In Tamura (2006) for instance, human capital accumulation lowers mortality, which in turn reduces fertility, thereby inducing a demographic transition and economic growth - lower fertility reduces the cost of human capital investment, inducing parents to invest more in the education of their children. It is not difficult to see in that setting how the lack of infrastructure can create another source of low-growth trap - poor transportation increases the time needed to get to school. ${ }^{27}$ And because the time spent to get to school raises the total amount of time that must be allocated to acquire skills, it increases the opportunity cost of education. Given the inability to borrow for poor households, parents tend to keep children out of school, because they are unable to cover the upfront cost of schooling (broadly defined to include

\footnotetext{
${ }^{26}$ Oketch (2006) found strong evidence that physical capital investment is critical to human capital accumulation and growth in Sub-Saharan Africa.

${ }^{27}$ The nonlinearity in the "learning curve" defined in Kejak (2003) for instance could be related to infrastructure.
} 
the opportunity cost of not working), in return for future (and uncertain) benefits. Of course, adding education could lead to additional sources of nonlinearities; in Mayer-Foulkes (2003, 2005) for instance, the acquisition of human capital is subject to threshold effects, with threshold levels depending endogenously on technological change and credit constraints.

Finally, it would be worth exploring another possible externality associated with infrastructure - regarding not the efficiency of public capital for a given technology (as was done here), but rather the choice of technology itself. At low levels of infrastructure, producers may have no choice but to adopt (or continue to use) a "subsistence" (or inefficient) technology. In the absence of a reliable power grid, for instance, firms may not be able to switch to more advanced machines and sophisticated equipment - even though it would be profitable to do so. With no roads to transport commodities between rural and urban areas in a timely fashion, the adoption of new production techniques in agriculture may not be feasible either. But once infrastructure provision has reached a certain threshold, producers may find it easier to adopt a "modern" (or highly productive) technology and reap the benefits from doing so. This, in turn, would lead to a faster pace of growth in output and sustained improvements in productivity. Endogenizing the switch in technology in this way would shed additional light on the development process while bringing to the fore the critical role of the state in fostering private sector growth. 


\section{Appendix}

The dynamic system consists of equations (23) and (24), which are repeated here for convenience:

$$
\begin{gathered}
\frac{\dot{c}}{c}=\xi k_{I}^{(\alpha+\mu \beta) / \Omega}-\chi\left(k_{I} ; \theta\right)+c \\
\frac{\dot{k}_{I}}{k_{I}}=v_{H}^{(1-\mu) \beta / \Omega} \theta^{\alpha / \Omega}\left\{\varphi v_{I} \tau^{1 / \Omega} k_{I}^{-\eta / \Omega}-(1-\tau) \tau^{(1-\mu) \beta / \Omega} k_{I}^{(\alpha+\mu \beta) / \Omega}\right\}+c
\end{gathered}
$$

where $\xi$ is defined in (25).

\section{Saddlepath Stability}

Consider first the case where $\theta$ is exogenous. In the vicinity of the steady state, equations (A1) and (A2) can be linearized to give

$$
\left[\begin{array}{c}
\dot{c} \\
\dot{k}_{I}
\end{array}\right]=\left[\begin{array}{cc}
a_{11} & a_{12} \\
a_{21} & a_{22}
\end{array}\right]\left[\begin{array}{c}
c-\tilde{c} \\
k_{I}-\tilde{k}_{I}
\end{array}\right]+\left[\begin{array}{cc}
a_{13} & 0 \\
a_{23} & a_{24}
\end{array}\right]\left[\begin{array}{c}
\theta \\
v_{I}
\end{array}\right],
$$

where $\tilde{c}$ and $\tilde{k}_{I}$ are interior stationary values of $c$ and $k_{I}$ and the $a_{i j}$ are given by

$$
\begin{gathered}
a_{11}=\tilde{c}>0, \quad a_{21}=\tilde{k}_{I}>0 \\
a_{12}=\tilde{c}\left(\frac{\alpha+\mu \beta}{\Omega \tilde{k}_{I}}\right) \xi \tilde{k}_{I}^{(\alpha+\mu \beta) / \Omega}-\tilde{c} \chi_{k_{I}} \\
a_{13}=\tilde{c}\left(\frac{\alpha}{\Omega \theta}\right) \xi \tilde{k}_{I}^{(\alpha+\mu \beta) / \Omega}-\tilde{c} \chi_{\theta} \\
a_{22}=\frac{v_{H}^{(1-\mu) \beta / \Omega} \theta^{\alpha / \Omega}}{\Omega}\left\{-\eta \varphi v_{I} \tau^{1 / \Omega} \tilde{k}_{I}^{-\eta / \Omega}-\Gamma \tau^{(1-\mu) \beta / \Omega} \tilde{k}_{I}^{(\alpha+\mu \beta) / \Omega}\right\}<0 \\
a_{23}=-\left(\frac{\alpha}{\Omega \theta}\right) \tilde{c}<0 \\
a_{24}=v_{H}^{(1-\mu) \beta / \Omega} \theta^{\alpha / \Omega} \varphi \tau^{1 / \Omega} \tilde{k}_{I}^{-\eta / \Omega}>0
\end{gathered}
$$

where $\Gamma \equiv(1-\tau)(\alpha+\mu \beta)>0 .{ }^{28}$ If $\rho^{\prime}$ is not too large, $a_{12}, a_{13}<0$.

\footnotetext{
${ }^{28}$ Note that, because in (A2) $k_{I}$ is raised to a negative power, $\tilde{k}_{I}=0$ cannot be a steady state. The economically meaningless case $\tilde{c}=0$ can also be ruled out.
} 
Because $c$ is a jump variable, whereas $k_{I}$ is predetermined, saddlepath stability requires one unstable (positive) root. To ensure that this condition holds, the determinant of the Jacobian matrix of partial derivatives of the dynamic system (A3), $J$, must be negative:

$$
\operatorname{det} J=a_{11} a_{22}-a_{12} a_{21}<0 .
$$

To examine if this condition holds, consider first the case where $\rho$ is constant (implying that the second term in the expression for $a_{12}$ is zero) and note that, from (A5) and (25), we have

$$
a_{12}=-\left(\frac{\tilde{c}}{\Omega \tilde{k}_{I}}\right)(\alpha+\beta)(\alpha+\mu \beta)\left\{(1-\tau)\left(v_{H} \tau\right)^{(1-\mu) \beta / \Omega} \theta^{\alpha / \Omega} \tilde{k}_{I}^{(\alpha+\mu \beta) / \Omega}\right\},
$$

or, using (28), and noting that $s / \eta=1-\tau$ and $-(\alpha+\beta) / \eta=1-\eta^{-1}$,

$$
a_{12}=\left(\frac{\tilde{c}}{\Omega \tilde{k}_{I}}\right)\left(1-\eta^{-1}\right)(\alpha+\mu \beta)(\gamma+\rho)<0 .
$$

Similarly, from (A6),

$$
a_{22}=-\frac{\eta \theta^{\alpha / \Omega}}{\Omega}\left\{\varphi v_{I} \tau^{1 / \Omega} v_{H}^{(1-\mu) \beta / \Omega} \tilde{k}_{I}^{-\eta / \Omega}\right\}-\frac{\Gamma}{s \Omega}\left\{s\left(v_{H} \tau\right)^{(1-\mu) \beta / \Omega} \tilde{k}_{I}^{(\alpha+\mu \beta) / \Omega}\right\},
$$

or, using (27) and (28),

$$
a_{22}=-\frac{\eta}{\Omega} \gamma-\frac{\Gamma}{s \Omega}(\gamma+\rho) .
$$

From (A4), (A7), and (A8),

$$
\Delta=-\frac{\tilde{c} \eta}{\Omega} \gamma-\frac{\tilde{c} \Gamma}{s \Omega}(\gamma+\rho)-\left(\frac{\tilde{c}}{\Omega}\right)\left(1-\eta^{-1}\right)(\alpha+\mu \beta)(\gamma+\rho),
$$

or equivalently, $\Delta=\Delta^{\prime} \tilde{c} / \Omega$ where

$$
\Delta^{\prime}=-\eta \gamma-\left\{\frac{\Gamma}{s}+\left(1-\eta^{-1}\right)(\alpha+\mu \beta)\right\}(\gamma+\rho),
$$

so that $\operatorname{sg}(\Delta)=\operatorname{sg}\left(\Delta^{\prime}\right)$.

From the definition of $\Gamma$, we have $\Gamma / s=(\alpha+\mu \beta) \eta^{-1}$. Thus

$$
\Delta^{\prime}=-\eta \gamma-(\alpha+\mu \beta)\left\{\eta^{-1}+\left(1-\eta^{-1}\right)\right\}(\gamma+\rho),
$$


that is

$$
\Delta^{\prime}=-\eta \gamma-(\alpha+\mu \beta)(\gamma+\rho)<0 .
$$

Thus, the saddlepath condition is always satisfied for $\rho$ constant. If $\rho$ is endogenous and $\rho^{\prime}$ is sufficiently large, $a_{12}$ may be positive, in which case (given that $a_{21}>0$ ), the condition $\operatorname{det} J<0$ always holds. In what follows, it is assumed that $\rho^{\prime}$ is small enough to ensure that $a_{12}$ remains negative.

With $a_{12}<0$, the slopes of lines $C C$ and $K K$ in Figure 1 are given by

$$
\begin{gathered}
\left.\frac{d c}{d k_{I}}\right|_{\dot{c}=0}=-\frac{a_{12}}{a_{11}}=-\left(\frac{\xi}{\Omega \tilde{k}_{I}}\right)(\alpha+\mu \beta) \tilde{k}_{I}^{(\alpha+\mu \beta) / \Omega}+\chi_{k_{I}}>0, \\
\left.\frac{d c}{d k_{I}}\right|_{\dot{k}_{I}=0}=-\frac{a_{22}}{a_{21}}=\frac{v_{H}^{(1-\mu) \beta / \Omega}}{\theta^{-\alpha / \Omega} \Omega \tilde{k}_{I}}\left\{\eta \varphi v_{I} \tau^{1 / \Omega} \tilde{k}_{I}^{-\eta / \Omega}+\Gamma \tau^{(1-\mu) \beta / \Omega} \tilde{k}_{I}^{(\alpha+\mu \beta) / \Omega}\right\}>0 .
\end{gathered}
$$

Saddlepath stability ( $\operatorname{det} A<0$ ) implies that line $K K$ in Figure 1 must be steeper than $C C$. The slope of the saddlepath $S S$, which is given by $-a_{12} /(\tilde{c}-\zeta)$, where $\zeta$ is the negative root of the system, is also positive.

\section{Uniqueness}

To see whether the equilibrium is unique, note that from (A1), setting $\dot{c}=0$ yields

$$
\tilde{c}=-\xi \tilde{k}_{I}^{(\alpha+\mu \beta) / \Omega}+\chi\left(\tilde{k}_{I} ; \theta\right) .
$$

Substituting (A11) in (A2) with $\dot{k}_{I}=0$ yields the implicit function

$$
F\left(\tilde{k}_{I}\right)=\chi\left(\tilde{k}_{I} ; \theta\right)+\left(v_{H} \tau\right)^{(1-\mu) \beta / \Omega} \theta^{\alpha / \Omega}\left\{\varphi v_{I} \tau \tilde{k}_{I}^{-\eta / \Omega}-s \tilde{k}_{I}^{(\alpha+\mu \beta) / \Omega}\right\}=0,
$$

from which it can be established that

$$
\left.F_{\tilde{k}_{I}}=\chi_{k_{I}}+\frac{\left(v_{H} \tau\right)^{(1-\mu) \beta / \Omega}}{\Omega \tilde{k}_{I}}\left\{-\eta \varphi v_{I} \tau \tilde{k}_{I}^{(\alpha \kappa-\eta) / \Omega}-(\alpha+\mu \beta)\right] s \tilde{k}_{I}^{[\alpha \kappa+(\alpha+\mu \beta)] / \Omega}\right\}<0 .
$$

Thus, $F\left(\tilde{k}_{I}\right)$ cannot cross the horizontal axis from below. Now, we also have $\lim _{\tilde{k}_{I} \rightarrow 0} F\left(\tilde{k}_{I}\right)=+\infty$ and $\lim _{\tilde{k}_{I} \rightarrow+\infty} F\left(\tilde{k}_{I}\right)=-\infty$. Given that $F\left(\tilde{k}_{I}\right)$ is a continuous, monotonically decreasing function of $\tilde{k}_{I}$, there is a unique positive value of $\tilde{k}_{I}$ that satisfies $F\left(\tilde{k}_{I}\right)=0$. From (A11), there is also a unique positive value of $\tilde{c}$. Thus, the BGP is unique, and the equilibrium is locally determinate. 


\section{Effects of an increase in $v_{I}$}

To establish the effect of an increase in $v_{I}$, note that from (A3), we have $d \tilde{c} /\left.d v_{I}\right|_{C C} ^{\tilde{k}_{I} \text { given }}=0$ and $d \tilde{c} /\left.d v_{I}\right|_{K K} ^{\tilde{k}_{I} \text { given }}=-a_{24} / a_{21}<0$. Thus, an increase in $v_{I}$ has no effect on curve $C C$ and shifts curve $K K$ downward and to the right in Figure 1. The steady-state effects on $\tilde{c}$ and $\tilde{k}_{I}$ are given by

$$
\frac{d \tilde{c}}{d v_{I}}=\frac{a_{12} a_{24}}{\Delta}>0, \quad \frac{d \tilde{k}_{I}}{d v_{I}}=\frac{-a_{11} a_{24}}{\Delta}>0
$$

which indicate that both $\tilde{c}$ and $\tilde{k}_{I}$ increase. ${ }^{29}$

\section{Threshold Effects and Multiple Equilibria}

Consider now the case where efficiency is subject to threshold effects. For $k_{I}<k_{I}^{L}$, and thus $\theta$ constant, stability conditions are those discussed previously. For $k_{I}>k_{I}^{L}$, by contrast, $\theta=\theta\left(k_{I}\right)$; to fix ideas, let $\theta=\theta_{0} k_{I}^{\kappa}$, where $\kappa=\kappa_{1}>1\left(\kappa=\kappa_{2}<1<\kappa_{1}\right)$ for the convex (concave) portion of the curve in Figure 2. The case of constant $\theta$ corresponds therefore to $\kappa=0$. For simplicity, I normalize $\theta_{0}$ to unity in what follows.

In this case, using (A1) and (25), the steady-state values of $c$ and $k_{I}$ must satisfy

$$
\tilde{c}=\chi\left(\tilde{k}_{I} ; \theta\right)-\xi^{\prime} \tilde{k}_{I}^{[\alpha \kappa+(\alpha+\mu \beta)] / \Omega},
$$

where $\xi^{\prime} \equiv-(1-\tau)(\alpha+\beta)\left(v_{H} \tau\right)^{(1-\mu) \beta / \Omega}=\xi$ with $\theta=1$. The slope of $C C$ is thus given by

$$
\left.\frac{d c}{d k_{I}}\right|_{\dot{c}=0}=\chi_{k_{I}}+\chi_{\theta} \kappa\left(\frac{\theta}{\tilde{k}_{I}}\right)-\xi^{\prime}\left[\frac{\alpha \kappa+(\alpha+\mu \beta)}{\Omega \tilde{k}_{I}}\right] \tilde{k}_{I}^{[\alpha \kappa+(\alpha+\mu \beta)] / \Omega}>0,
$$

which is steeper than than the case where $\kappa=0$, under the assumption above on $\rho^{\prime}$ (which also implies that $\chi_{\theta}$ is not too large); see (A9).

Similarly, using (A2) and (25), the steady-state values of $c$ and $k_{I}$ must satisfy

$$
\tilde{c}=\tilde{k}_{I}^{\alpha \kappa / \Omega}\left[\varepsilon_{1} \tilde{k}_{I}^{(\alpha+\mu \beta) / \Omega}-\varepsilon_{2} \tilde{k}_{I}^{-\eta / \Omega}\right],
$$

where $\varepsilon_{1} \equiv(1-\tau)\left(v_{H} \tau\right)^{(1-\mu) \beta / \Omega}>0$, and $\varepsilon_{2} \equiv v_{H}^{(1-\mu) \beta / \Omega} \varphi v_{I} \tau^{1 / \Omega}>0$. To ensure that the consumption-private capital ratio is positive requires

\footnotetext{
${ }^{29}$ Equation (A3) can also be used to study the effects of an increase in $\theta$. Given the signs of $a_{13}$ and $a_{23}$, it can readily be established that the impact on $\tilde{c}$ and $\tilde{k}_{I}$ is in general ambiguous.
} 
imposing $\varepsilon_{1} \tilde{k}_{I}^{(\alpha+\mu \beta) / \Omega}-\varepsilon_{2} \tilde{k}_{I}^{-\eta / \Omega}>0$, or equivalently (after simplification) $\tilde{k}_{I}>\varphi v_{I} \tau^{1 / \Omega} /(1-\tau)$.

Given this result, the slope of curve $K K$ is now given by

$$
\begin{gathered}
\left.\frac{d c}{d k_{I}}\right|_{\dot{k}_{I}=0}=\frac{\alpha \kappa \theta^{\alpha / \Omega}}{\Omega \tilde{k}_{I}}\left[\varepsilon_{1} \tilde{k}_{I}^{(\alpha+\mu \beta) / \Omega}-\varepsilon_{2} \tilde{k}_{I}^{-\eta / \Omega}\right] \\
+\frac{\theta^{\alpha / \Omega}}{\Omega \tilde{k}_{I}}\left[\varepsilon_{1}(\alpha+\mu \beta) \tilde{k}_{I}^{(\alpha+\mu \beta) / \Omega}+\varepsilon_{2} \eta \tilde{k}_{I}^{-\eta / \Omega}\right]>0,
\end{gathered}
$$

which again is steeper than in the case where $\kappa=0$; see (A10).

To examine the issue of multiplicity of equilibria, combine (A14) with (A15) to give

$$
F\left(\tilde{k}_{I} ; \kappa\right)=\chi\left(\tilde{k}_{I} ; \theta\right)+\left(v_{H} \tau\right)^{(1-\mu) \beta / \Omega}\left\{\varphi v_{I} \tau \tilde{k}_{I}^{(\alpha \kappa-\eta) / \Omega}-s \tilde{k}_{I}^{[\alpha \kappa+(\alpha+\mu \beta)] / \Omega}\right\}=0
$$

so that

$$
\begin{gathered}
F_{\tilde{k}_{I}}=\chi_{k_{I}}+\chi_{\theta} \kappa\left(\frac{\theta}{\tilde{k}_{I}}\right)+\frac{\left(v_{H} \tau\right)^{(1-\mu) \beta / \Omega}}{\Omega \tilde{k}_{I}} \times \\
\times\left\{(\alpha \kappa-\eta) \varphi v_{I} \tau \tilde{k}_{I}^{(\alpha \kappa-\eta) / \Omega}-[\alpha \kappa+(\alpha+\mu \beta)] s \tilde{k}_{I}^{[\alpha \kappa+(\alpha+\mu \beta)] / \Omega}\right\} .
\end{gathered}
$$

With $\theta$ constant and $\kappa=0$, expression (A16) boils down to (A12). Now, although the second term on the right-hand side of (A16) is unambiguously negative, and $\alpha \kappa+(\alpha+\mu \beta)>0, F_{\tilde{k}_{I}}$ is no longer necessarily negative (as in (A13a) because the first term in the parentheses can be positive, depending on the value of $\alpha \kappa-\eta$. If the elasticity of time preference with respect to $\theta$ is not too high, (so that $\chi_{\theta}$ is not large) and the expression in parentheses remains positive, $F_{\tilde{k}_{I}}$ can be positive for some interval if externalities are strong ( $\kappa$ is high).

In that case, because the limit conditions given above still hold with endogenous $\theta$, (that is, $\lim _{\tilde{k}_{I} \rightarrow 0} F\left(\tilde{k}_{I} ; \kappa\right)=+\infty$, and $\left.\lim _{\tilde{k}_{I} \rightarrow+\infty} F\left(\tilde{k}_{I} ; \kappa\right)=-\infty\right)$, $F\left(\tilde{k}_{I} ; \kappa\right)$ may intersect the horizontal axis more than once. Assuming that the value of $k_{I}$ at which the derivative changes sign is larger than the threshold level $k_{I}^{L}$ at which the efficiency externality kicks in, and that the externality is very strong, the curve might intersect the horizontal axis from above, and take negative values for some interval before the derivative turns positive and starts increasing to cross the horizontal axis once more (this time from below), and then fall again after the upper threshold value $k_{I}^{H}$ is exceeded. 
In that situation, we will observe three equilibria. Or, if the externalities are strong but not excessively so, the curve might cut the horizontal axis from above and take negative values for some interval, as before, but this time around it may increase until it becomes tangent to the horizontal axis at exactly $k_{I}^{H}$ and start falling to $-\infty$, as $k_{I}$ rises further. In such conditions, we will observe two equilibria, only the first of which is stable. Finally, with weak externality effects, the curve might increase as before but not enough to cross the horizontal axis from below - so that $F\left(\tilde{k}_{I}\right)$ remains strictly negative - and a unique equilibrium may emerge.

Formally, for $\kappa \neq 0$ the case of no equilibrium corresponds to $F_{\tilde{k}_{I}}>0$, given that in that case $F\left(\tilde{k}_{I} ; \kappa\right)=0$ cannot be achieved $\forall \tilde{k}_{I}$. In turn, for $F_{\tilde{k}_{I}}>0$, a necessary (although not sufficient) condition is $\kappa>\eta / \alpha$. However, because of threshold effects in efficiency, we may also have no equilibrium even if $F_{\tilde{k}_{I}}<0$ initially (which is always the case for $\kappa=0$, as implied by (A13a)), as long as the following conditions are satisfied:

a) the value of $\tilde{k}_{I}$ at which $F\left(\tilde{k}_{I} ; 0\right)=0$ exceeds $k_{I}^{L}$;

$b)$ the value of $\tilde{k}_{I}$ at which $F\left(\tilde{k}_{I} ; \kappa_{1}\right)=0$ exceeds $k_{I}^{H}$;

c) $F_{\tilde{k}_{I}}>0$ for $\kappa=\kappa_{2}$.

For a unique equilibrium, we must have one of the following conditions:

a) $F_{\tilde{k}_{I}}<0$ for $\kappa=0$, and the value of $\tilde{k}_{I}$ at which $F\left(\tilde{k}_{I} ; 0\right)=0$ is less than $k_{I}^{L}$, and $F_{\tilde{k}_{I}}>0$ for both $\kappa=\kappa_{1}$ and $\kappa=\kappa_{2}$;

b) $F_{\tilde{k}_{I}}<0$ for $\kappa=0$, the value of $\tilde{k}_{I}$ at which $F\left(\tilde{k}_{I} ; \kappa\right)=0$ exceeds $k_{I}^{L}$ for $\kappa=0$ but is less than $k_{I}^{H}$ for $\kappa=\kappa_{1}, F_{\tilde{k}_{I}}<0$ for $\kappa=\kappa_{1}$, and $F_{\tilde{k}_{I}}>0$ for $\kappa=\kappa_{2}$

c) $F_{\tilde{k}_{I}}<0$ for $\kappa=0$, the value of $\tilde{k}_{I}$ at which $F\left(\tilde{k}_{I} ; \kappa\right)=0$ exceeds $k_{I}^{L}$ and $k_{I}^{H}$ for $\kappa=0$ and $\kappa=\kappa_{1}$, respectively, and $F_{\tilde{k}_{I}}<0$ for $\kappa=\kappa_{2}$. In this case, $F_{\tilde{k}_{I}} \lessgtr 0$ for $\kappa=\kappa_{1}$, given that $\kappa_{1}>\kappa_{2}$.

For multiple equilibria, one of them unstable, we must have all of the following conditions:

a) $F_{\tilde{k}_{I}}<0$ for $\kappa=0$, and the value of $\tilde{k}_{I}$ at which $F\left(\tilde{k}_{I} ; 0\right)=0$ is less than $k_{I}^{L}$;

b) $F_{\tilde{k}_{I}}>0$ for $\kappa=\kappa_{1}$, the value of $\tilde{k}_{I}$ at which $F\left(\tilde{k}_{I} ; \kappa_{1}\right)=0$ exceeds $k_{I}^{L}$ but is less than $k_{I}^{H}$;

c) $F_{\tilde{k}_{I}}<0$ for $\kappa=\kappa_{2}$, the value of $\tilde{k}_{I}$ at which $F\left(\tilde{k}_{I} ; \kappa_{2}\right)=0$ exceeds $k_{I}^{H}$.

Thus, in general, the slopes of $C C$ and $K K$ will vary between the intervals $k_{I}<k_{I}^{L}, k_{I} \in\left(k_{I}^{L}, k_{I}^{H}\right)$, and $k_{I}>k_{I}^{H}$, depending on the value of $\kappa$. As shown in Figures 3, 4, and 5, which are all based on the linearized dynamic system, 
various cases are possible, corresponding to the results above; lines $C C$ and $K K$ may not intersect at all (Figure 3), they may intersect once (Figure 4), twice (not shown), or they may intersect three times (Figure 5). In the latter case, stability depends now on the eigenvalues corresponding to the Jacobian matrix calculated around each steady state. As noted earlier, saddlepath stability requires det $J<0 ; K K$ must cut $C C$ from below. This is the case at points $E^{1}$ and $E^{3}$ in Figure 5 . Point $E^{2}$ is therefore an unstable equilibrium. 


\section{References}

Acemoglu, Daron, and Simon Johnson, "Disease and Development: The Effect of Life Expectancy on Economic Growth," Journal of Political Economy, 115 (December 2007), 925-85.

Agénor, Pierre-Richard, "Health and Infrastructure in a Model of Endogenous Growth," Journal of Macroeconomics, 30 (December 2008), 1407-22.

Agénor, Pierre-Richard, "Public Capital, Health Persistence and Poverty Traps," Working Paper No. 115, Centre for Growth and Business Cycle Research, University of Manchester (February 2009a).

- - Public Capital, Growth, and Welfare, book in progress, University of Manchester (December 2009b).

Agénor, Pierre-Richard, and Peter J. Montiel, Development Macroeconomics, 3rd ed., Princeton University Press (Princeton, New Jersey: 2008).

Agénor, Pierre-Richard, and Kyriakos Neanidis, "The Allocation of Public Expenditure and Economic Growth," Working Paper No. 69, Centre for Growth and Business Cycle Research, University of Manchester (March 2006). Forthcoming, Manchester School of Social and Economic Studies.

Aísa, Rosa, and F. Pueyo, "Government Health Spending and Growth in a Model of Endogenous Longevity," Economics Letters, 90 (February 2006), 249-53.

Arestoff, Florence, and Christophe Hurlin, "Threshold Effects in the Productivity of Public Capital in Developing Countries," unpublished, University of Orléans (May 2005).

Azariadis, Costas, "The Theory of Poverty Traps: What Have we Learned?," in Poverty Traps, ed. by Samuel Bowles, Steven N. Durlauf, and Karla Hoff, Princeton University Press (Princeton, New Jersey: 2006).

Bertocchi, Graziella, and Fabio Canova, "Did Colonization Matter for Growth? An Empirical Exploration into the Historical Causes of Africa's Underdevelopment," European Economic Review, 46 (December 2002), 1851-71.

Blackburn, Keith, and Giam P. Cipriani, "A Model of Longevity and Growth," Journal of Economic Dynamics and Control," 26 (February 2002), 187-204.

Blanchard, Olivier J., "Debt, Deficits, and Finite Horizons," Journal of Political Economy, 93 (April 1985), 223-47.

Blanchard, O. J., Fischer, S., 1989. Lectures on Macroeconomics. MIT Press, Cambridge, Mass.

Boucekkine, Raouf, David de la Croix, and Omar Licandro, "Early Mortality Declines at the Dawn of Modern Economic Growth," Scandinavian Journal of Economics, 105 (September 2003), 401-18. 
Buiter, Willem H., "Death, Birth, Productivity Growth and Debt Neutrality," Economic Journal, 98 (June 1988), 279-93.

Bunzel, Helle, and Xue Qiao, "Endogenous Lifetime and Economic Growth Revisited," Economics Bulletin, 8 (February 2005), 1-8.

Cazzavillan, Guido, "Public Spending, Endogenous Growth, and Endogenous Fluctuations," Journal of Economic Theory, 71 (November 1996), 394-415.

Chakraborty, Shankha, "Endogenous Lifetime and Economic Growth," Journal of Economic Theory, 116 (May 2004), 119-37.

Chen, Been-Lon, "Public Capital, Endogenous Growth, and Endogenous Fluctuations," Journal of Macroeconomics, 28 (December 2006), 768-74.

Cooper, Frederick, "Africa and the World Economy," in Frederick Cooper, Allen F. Isaacman, Florencia E. Mallon, and Steve J. Stern, Confronting Historical Paradigms, University of Wisconsin Press (Madison, Wisconsin: 1993).

Dasgupta, Partha, "Nutritional Status, the Capacity for Work, and Poverty Traps," in Labour Markets, Poverty, and Development, ed. by Giorgio Barba Navaretti, Riccardo Faini, and Giovanni Zanalda, Oxford University Press (New York: 1999).

Economides, Nicholas, "The Economics of Networks," International Journal of Industrial Organization, 14 (October 1996), 669-71.

Ehrlich, Isaac, and Jinyoung Kim, "Endogenous Fertility, Mortality and Economic Growth: Can a Malthusian Framework Account for the Conflicting Historical Trends in Population?," Journal of Asian Economics, 16 (October 2005), 789-806.

Eicher, T., Turnovsky, S. J., 1999. Non-scale models of endogenous growth. Economic Journal 109, 394-415.

Epstein, Larry G., and J. Allan Hynes, "The Rate of Time Preference and Dynamic Economic Analysis," Journal of Political Economy, 81 (August 1983), 611-35.

Fernald, John G., "Roads to Prosperity? Assessing the Link between Public Capital and Productivity," American Economic Review, 89 (June 1999), 61938.

Fogel, Robert W., "Economic Growth, Population Theory, and Physiology: The Bearing of Long-Term Processes on the Making of Economic Policy," American Economic Review, 83 (June 1994), 369-95.

_ , "New Findings on Secular Trends in Nutrition and Mortality: Some Implications for Population Theory," in Handbook of Population and Family Economics, Vol. 1A, ed. by Mark Rosenzweig and Oded Stark (Amsterdam: 1997). 
Frederick, Shane, George Loewenstein, and Ted O'Donoghue, "Time Discounting and Time Preference: A Critical Review," Journal of Economic Literature, 40 (June 2002), 351-401.

Futagami, Koichi, and Kazuo Mino, "Public Capital and Patterns of Growth in the Presence of Threshold Externalities," Journal of Economics, 61 (June 1995), 123-46.

Hashimoto, Ken-ichi, and Ken Tabata, "Health Infrastructure, Demographic Transition and Growth," Review of Development Economics, 9 (November 2005), 549-62.

Hurlin, Christophe, "Network Effects of the Productivity of infrastructure in Developing Countries," Policy Research Working Paper No. 3808, World Bank (January 2006).

Kam, Eric, "A Note on Time Preference and the Tobin Effect," Economics Letters, 89 (October 2005), 127-32.

Kejak, Michal, "Stages of Growth in Economic Development," Journal of Economic Dynamics and Control, 27 (March 2003), 771-800.

Kosempel, Stephen, "A Theory of Development and Long Run Growth," Journal of Development Economics, 75 (October 2004), 201-20.

Lawrance, Emily C., "Poverty and the Rate of Time Preference: Evidence from Panel Data," Journal of Political Economy, 99 (February 1991), 54-78.

Lorentzen, Peter, John McMillan, and Romain Wacziarg, "Death and Development," Journal of Economic Growth, 13 (June 2008), 81-124.

Matsuyama, Kiminori, "Increasing Returns, Industrialization, and Indeterminacy of Equilibrium," Quarterly Journal of Economics, 106 (May 1991), $617-50$.

Mayer-Foulkes, David, "Human Development and Economic Growth: From Stagnation to Stratified and Transitional Growth," CIDE (May 2003).

— - "Human Development Traps and Economic Growth," in Health and Economic Growth: Findings and Policy Implications, ed. by Guillem LópezCasasnovas, Berta Rivera and Luis Currais, MIT Press (Boston: 2005).

Millennium Project, Investing in Development: A Practical Plan to Achieve the Millennium Development Goals, Report to the United Nations Secretary General, New York (January 2005).

Mohsin, Mohammed, "Exchange Rate Policies and Endogenous Time Preference: A Dynamic Analysis of a Small Open Economy," Economics Letters, 82 (February 2004), 195-203.

Obstfeld, Maurice, "Intertemporal Dependence, Impatience, and Dynamics," Journal of Monetary Economics, 26 (August 1990), 45-75. 
Oketch, Moses O., "Determinants of Human Capital Formation and Economic Growth of African Countries," Economics of Education Review, 25 (October 2006), 554-64.

Robinson, James A., and Ragnar Torvik, "White Elephants," Journal of Public Economics, 89 (February 2005), 197-210.

Rodney, Walter, How Europe Underdeveloped Africa, Bogle-L'Ouverture Publications (London: 1973).

Rosenstein-Rodan, Paul N., "Problems of Industrialisation of Eastern and SouthEastern Europe," Economic Journal, 53 (June 1943), 202-11.

Sachs, Jeffrey, The End of Poverty: Economic Possibilities for our Time, Penguin Press (New York, NY: 2005).

Sala-i-Martin, Xavier, "On the Health-Poverty Trap," in Health and Economic Growth: Findings and Policy Implications, ed. by Guillem López-Casasnovas, Berta Rivera and Luis Currais, MIT Press (Boston, Mass.: 2005).

Sohn, B., "How Much Has Health Improvement Contributed to Korean Economic Growth?," unpublished, Brown University (June 2000).

Shi, Shouyong, and Larry G. Epstein, "Habits and Time Preference," International Economic Review, 34 (February 1993), 61-84.

Svensson, Jakob, "Foreign Aid and Rent-Seeking," Journal of International Economics, 51 (August 2000), 437-61.

Tamura, Robert, "Human Capital and Economic Development," Journal of Development Economics, 79 (January 2006), 26-72.

Uzawa, Hirofumi, "Time Preference, the Consumption Function, and Optimal Asset Holdings," in Value, Capital and Growth, ed. by J. N. Wolfe, Aldine Publishing (Chicago, Il.: 1968).

Wagstaff, Adam, and Mariam Claeson, The Millennium Development Goals for Heath: Rising to the Challenges, World Bank (Washington DC: 2004).

Wang, Limin, "Determinants of Child Mortality in LDCs: Empirical Findings from Demographic and Health Surveys," Health Policy, 65 (September 2003), 277-99.

World Bank, Investing in Infrastructure, World Development Report 1994, Oxford University Press (New York: 1994).

Yaari, Menahem E., "Uncertain Lifetime, Life Insurance, and the Theory of the Consumer," Review of Economic Studies, 32 (June (1965), 137-50.

Yoshino, Yutaka, "Domestic Constraints, Firm Characteristics, and Geographical Diversification of Firm-Level Manufacturing Exports in Africa," Policy Research Working Paper No. 4575, World Bank (March 2008). 
Figure 1

Increase in the Share of Spending on Infrastructure

Financed by a Cut in Unproductive Spending

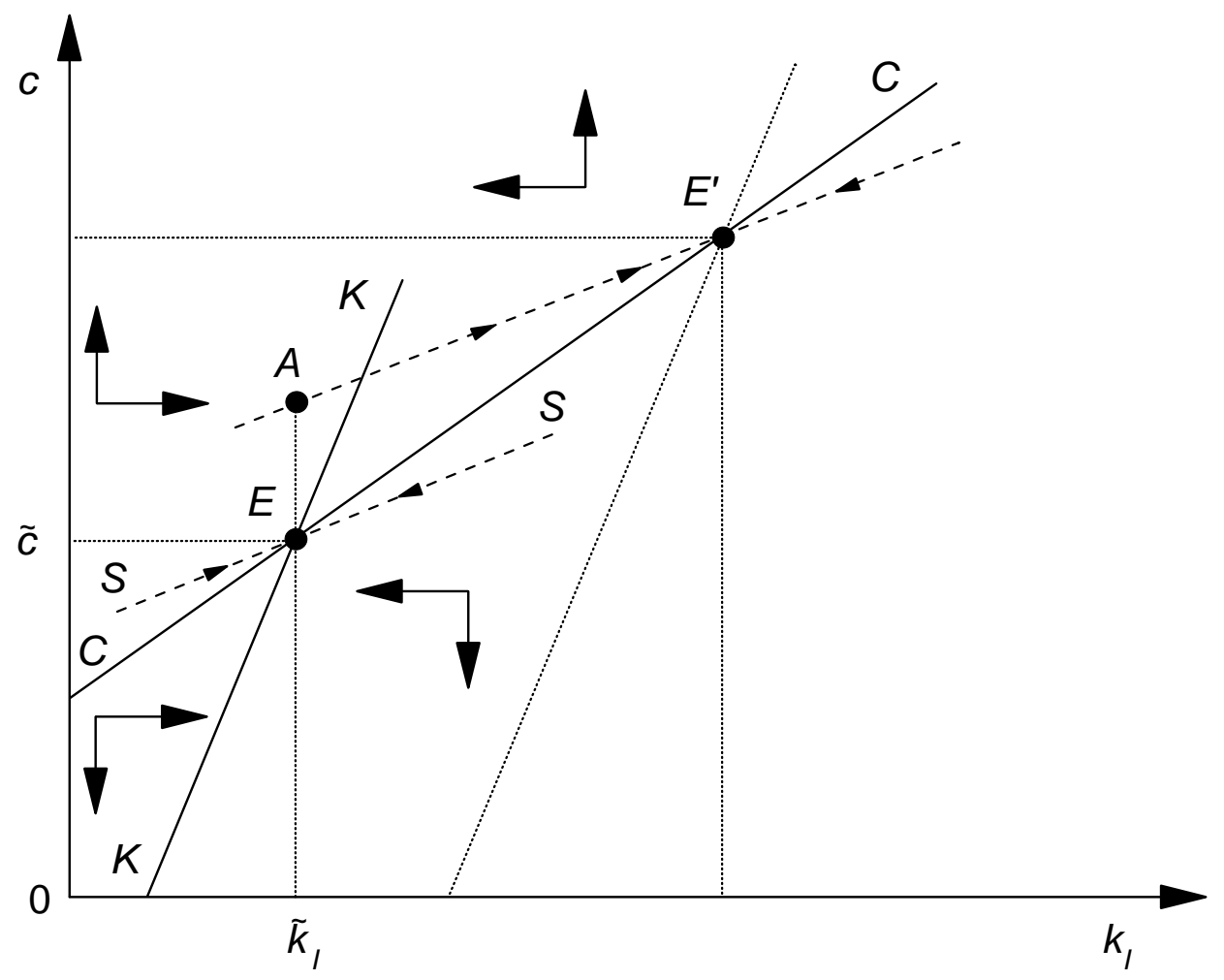


Figure 2

Network Externalities and Endogenous Efficiency

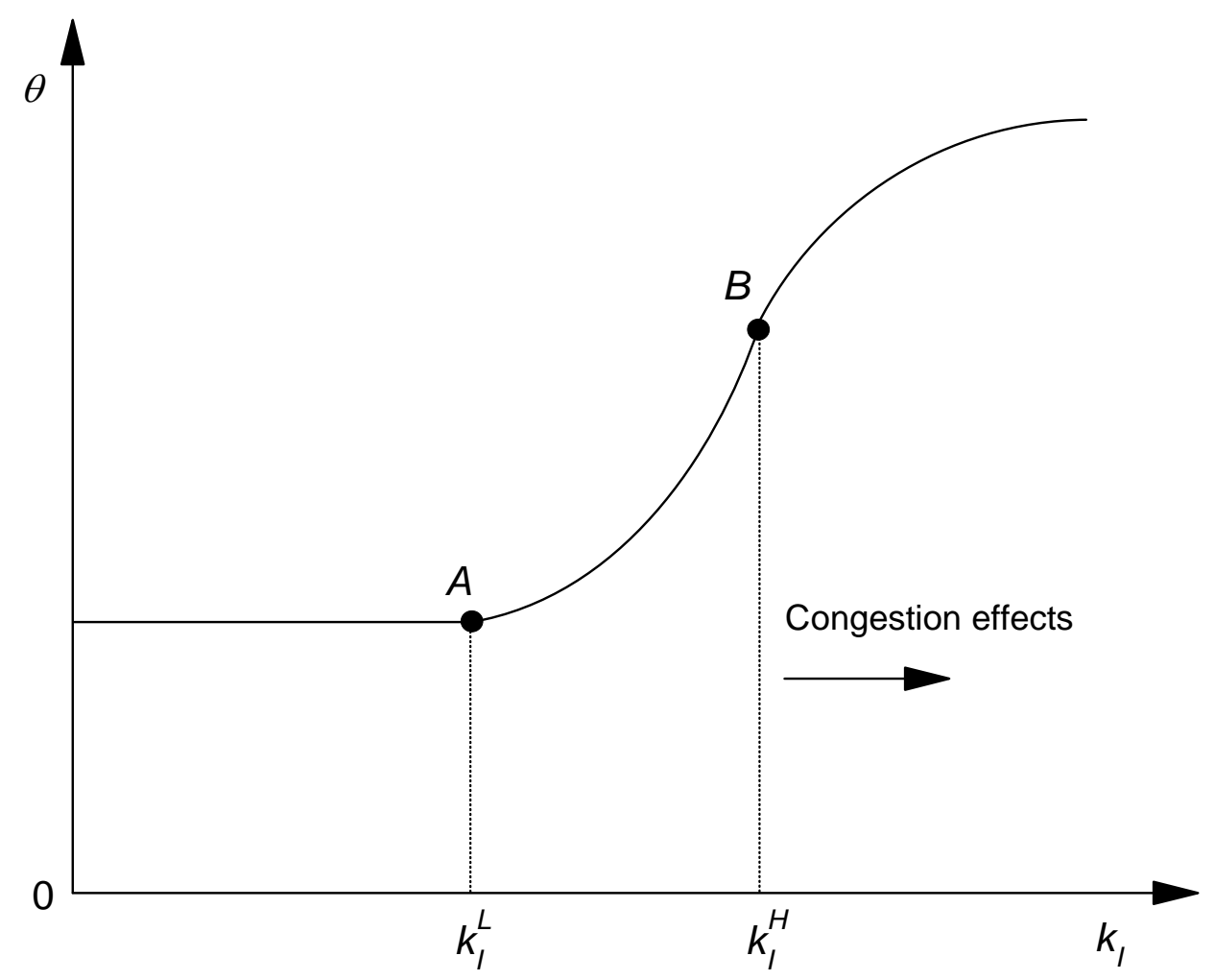


Figure 3

Network Externalities: No Equilibrium

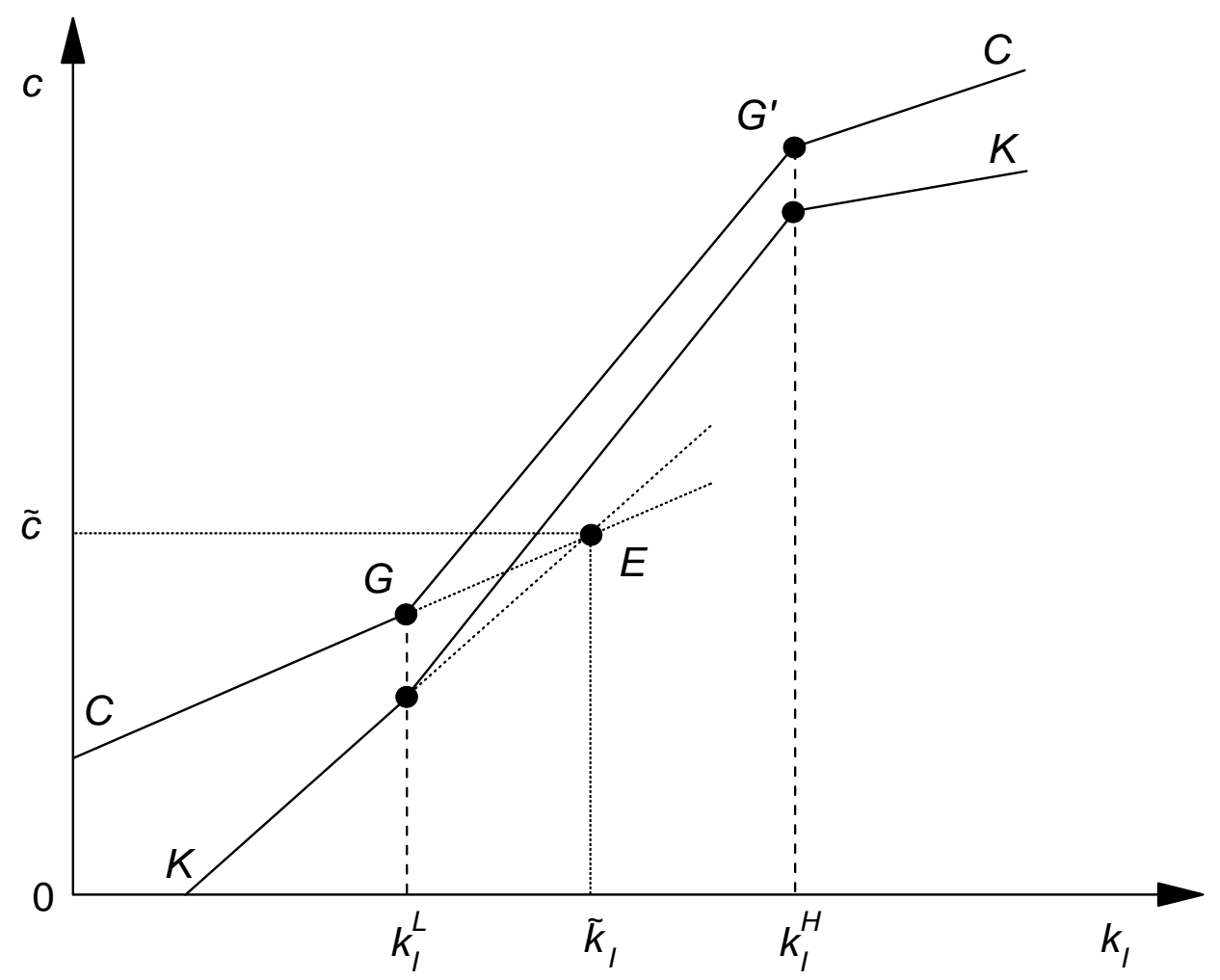


Figure 4

Network Externalities: Unique Equilibrium
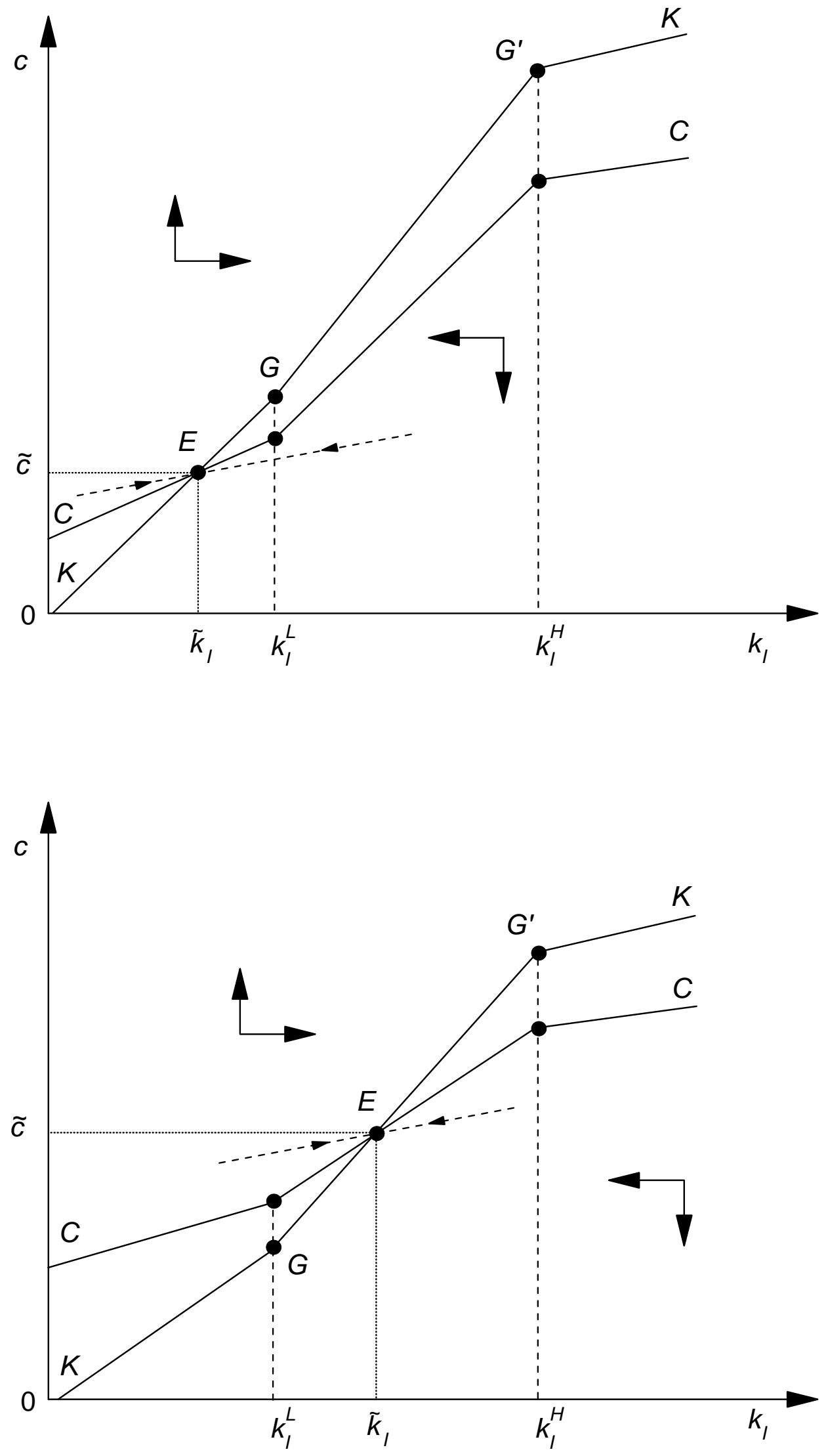
Figure 5

Network Externalities: Multiple Equilibria

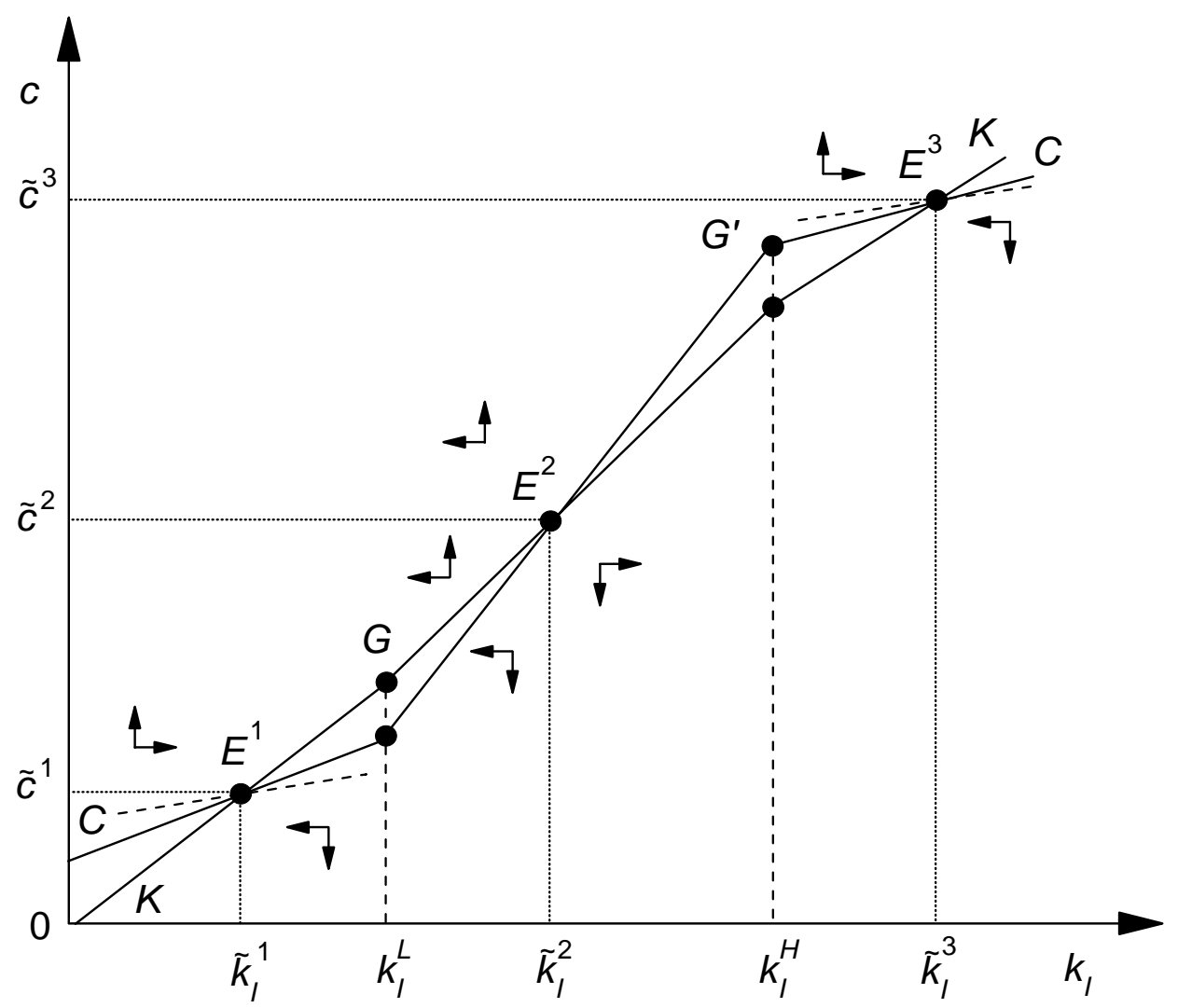


Figure 6

Trajectories around the Unstable Equilibrium

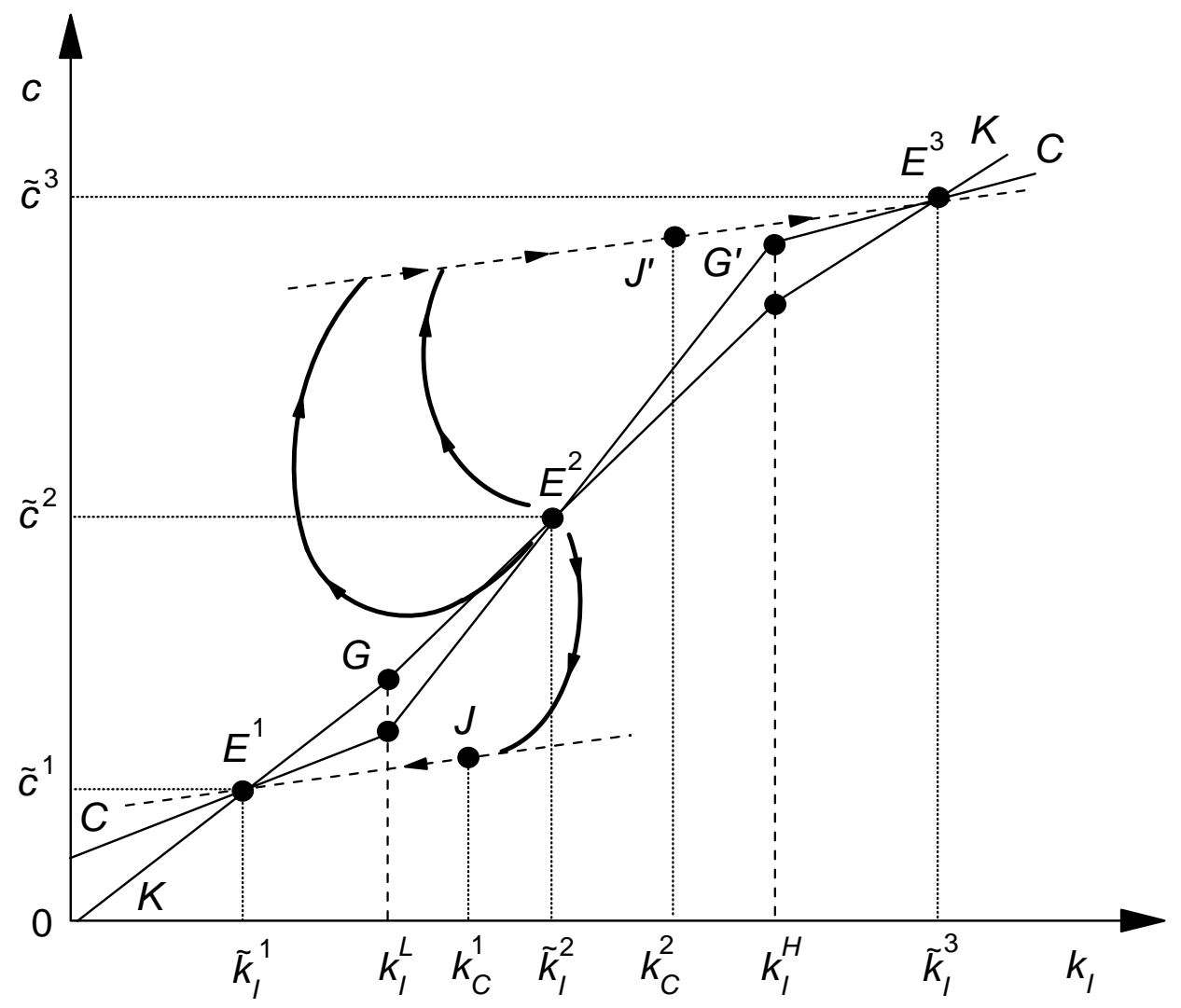


Figure 7

Shift in Spending toward Infrastructure: Unique Equilibrium
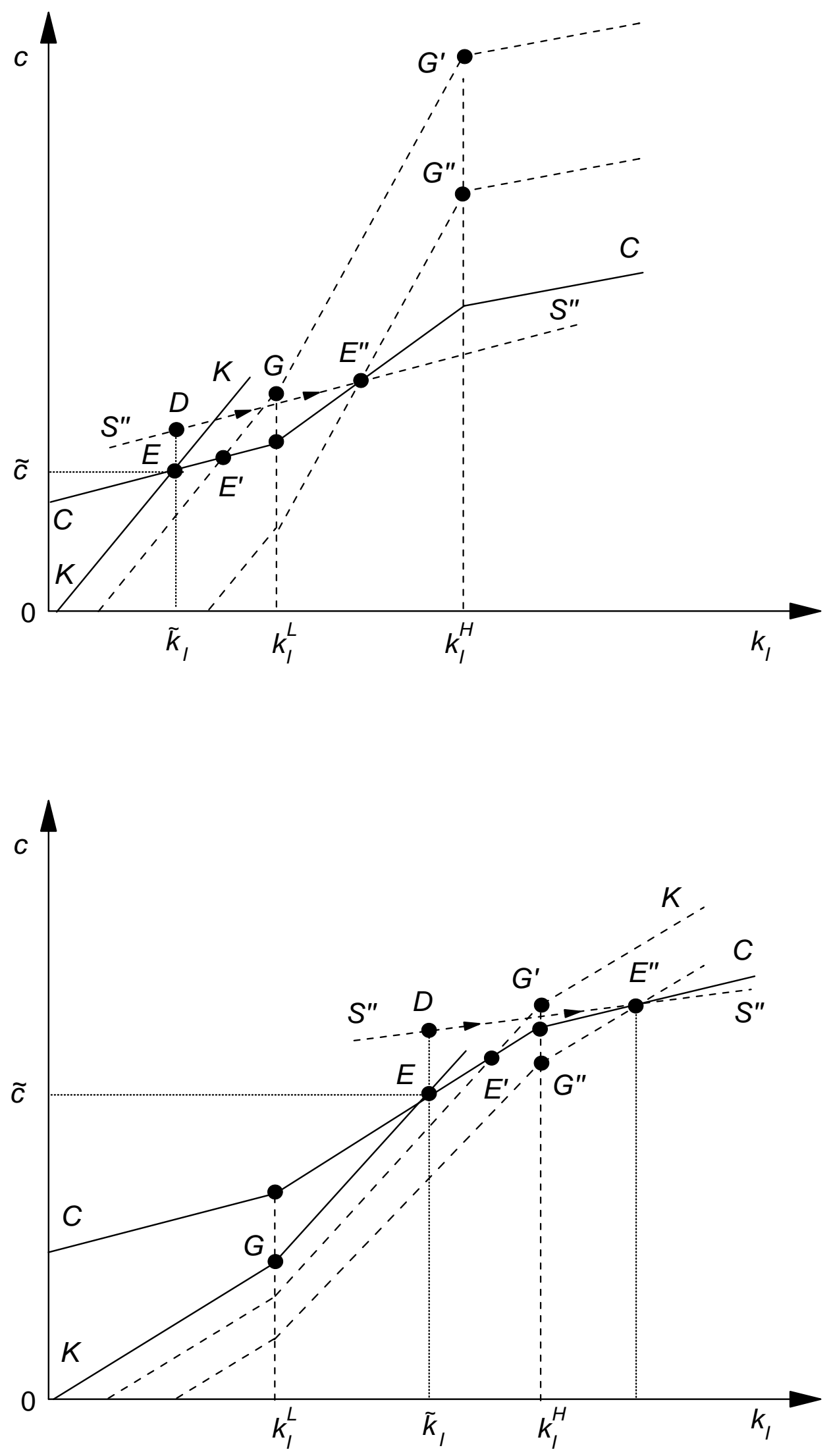
Figure 8

Shift in Spending toward Infrastructure: Multiple Equilibria

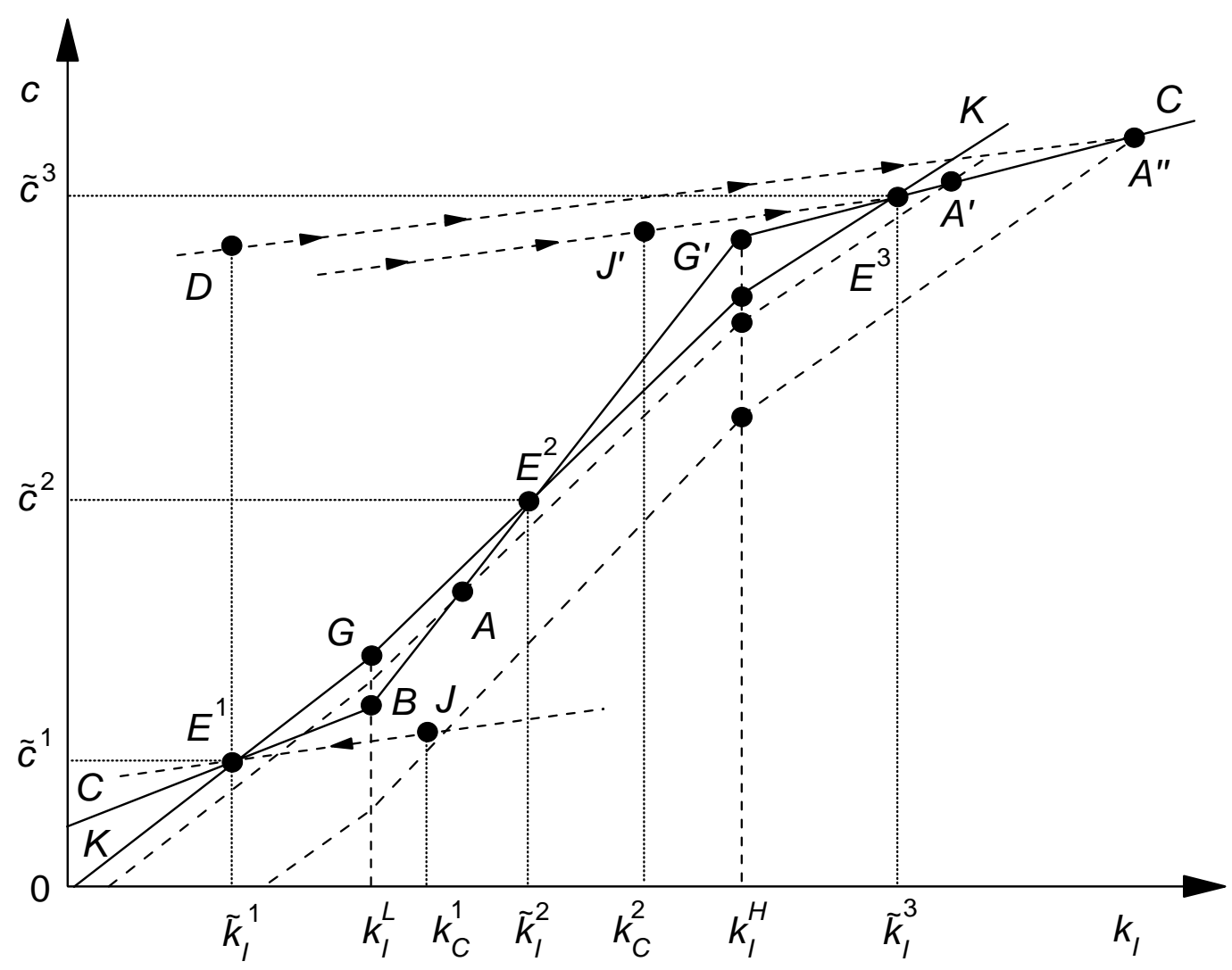

